\title{
1 Probing the DPRK nuclear test-site down to low seismic magnitude
}

\section{Steven J. Gibbons ${ }^{1}$, Tormod Kværna ${ }^{1}$, Sven Peter Näsholm ${ }^{1}$ and Svein Mykkeltveit ${ }^{1}$}

\section{ABSTRACT}

On 3 September 2017, the Democratic People's Republic of Korea (DPRK) carried out its sixth declared underground nuclear test (NK6) at the Punggye-ri test-site. With body wave magnitude 6.1, this explosion was significantly larger than any of the previous five explosions and it has been followed by numerous smaller seismic events. The explosion generated seismic waves dominated by significantly lower frequencies than the earlier tests which makes accurate measurement of relative time-delays using cross-correlation challenging. Finding a frequency band at which one observes common features in the NK6 signals and the corresponding signals from an earlier event can result in reduced signal to noise ratio. Classical double-difference location estimates for NK6 show a significant spread, depending upon the set of measurements used. We treat the first five declared DPRK explosions as a source array and demonstrate, using a geometrical argument about the relative time-shifts visible between the signals on pairs of stations, that NK6 was very close to the 9 September 2016 explosion (NK5) - assumed to be close to maximal overburden beneath the summit of Mount Mantap. In addition to the magnitude 4.1 presumed collapse event 8 minutes after NK6, numerous other small events have been observed at or close to the test-site since September 2017. We demonstrate how the test-site is monitored to magnitudes below 2 using multichannel correlation templates from all existing observations. Processing all available historical data from the KSRS and USRK arrays reveals a few small events in 2013, 2014, and 2016 which are similar in nature to those observed in late 2017. This suggests that the more recent low magnitude events are not simply a direct result of NK6. We urge caution in the interpretation of the correlation functions between the signals from different events at or close to the test-site since the signals are a function of both the source term and of near-source structure, with the effects of topography likely to be significant.

Contact details for all authors at the time was submission was NORSAR, Kjeller, Norway: tormod@norsar.no,peter@norsar.no, svein@norsar.no Current address for SJG: Norges Geotekniske Institutt, Sognsveien 72, 0855, Oslo steven.gibbons@ngi.no

\footnotetext{
${ }^{1}$ NORSAR, Kjeller, Norway.
} 
Pre-acceptance postprint: final paper published on https://doi.org/10.1785/0220180116

Probing the DPRK Nuclear Test Site down to Low-Seismic Magnitude:

Seismological Research Letters (2018) 89 (6): 2034-2041,

S. J. Gibbons, T. Kværna, S. P. Näsholm, S. Mykkeltveit

\section{INTRODUCTION}

A seismic disturbance in the Democratic People's Republic of Korea (the DPRK or North Korea) with a body wave magnitude 6.1 was detected on Sunday 3 September 2017 by seismometers around the globe. An estimated origin time of 03:30:00 UT and coordinates $41.23^{\circ} \mathrm{N}$ and $129.08^{\circ} \mathrm{E}$ made the seismic recordings consistent with a declared nuclear test at the Punggye-ri test-site at 12:00 noon local time. The signal amplitudes indicated that the seismic event associated with the September 2017 nuclear test (hereafter NK6) was a full unit of magnitude larger than for the previous test of 9 September 2016 (NK5), and with over a factor of ten increase in the estimated yield compared with the previous tests. The explosion differed from the previous tests also in other ways. Firstly, approximately 8.5 minutes after the estimated explosion time, a seismic event of magnitude 4.1 with non-explosion-like characteristics was detected and attributed a source location at the test site. This was the first time following a DPRK nuclear test that a presumed collapse event had been detected at significant distances from the source (Liu et al., 2018, Wang et al., 2018); the 11 September 2016 presumed collapse event following NK5 (Adushkin et al., 2017) had only been detected at regional distances. Secondly, in the months following the test, numerous smaller seismic events have been detected and attributed a location at or close to the test-site. The nature of these events is currently unclear although the characteristics of the seismic signals generated are very unlike those generated by the declared nuclear tests.

The signals generated by NK6 are dominated by lower frequencies than those generated by the earlier explosions. This complicates the relative event location procedure using classical doubledifference algorithms since it is more difficult to measure accurate time-delay estimates. We will argue, based only on the observations from four seismic arrays of the International Monitoring System (IMS), that NK6 took place very close to the location of NK5. The existing relative location estimates for the first five declared nuclear tests provide a frame of reference which sets very tight constraints on the location of NK6. We provide an overview of lower magnitude seismic events located at or close to the test-site. What can we infer about these events based upon waveform similarity alone? What is the optimal procedure for detecting such events, and down to what thresholds can we confidently detect and identify events close to the test-site? 
Pre-acceptance postprint: final paper published on https://doi.org/10.1785/0220180116 Probing the DPRK Nuclear Test Site down to Low-Seismic Magnitude:

Seismological Research Letters (2018) 89 (6): 2034-2041,

S. J. Gibbons, T. Kværna, S. P. Näsholm, S. Mykkeltveit

\section{GEOLOCATION OF THE 3 SEPTEMBER 2017 NUCLEAR TEST}

Accurate relative location estimates for the North Korean nuclear tests are not simply a seismological curiosity. They provide geometrical constraints on the possible absolute event locations within the steep-sided terrain at the test-site and, combined with satellite imagery and other intelligence, provide insights into possible developments and strategy. An accurate absolute event location will provide an estimate of the likely overburden from which we can place constraints upon the likely yield, and may facilitate realistic computational models of how the wavefield evolves in different directions under the influence of topography (e.g. Rodgers et al., 2010).
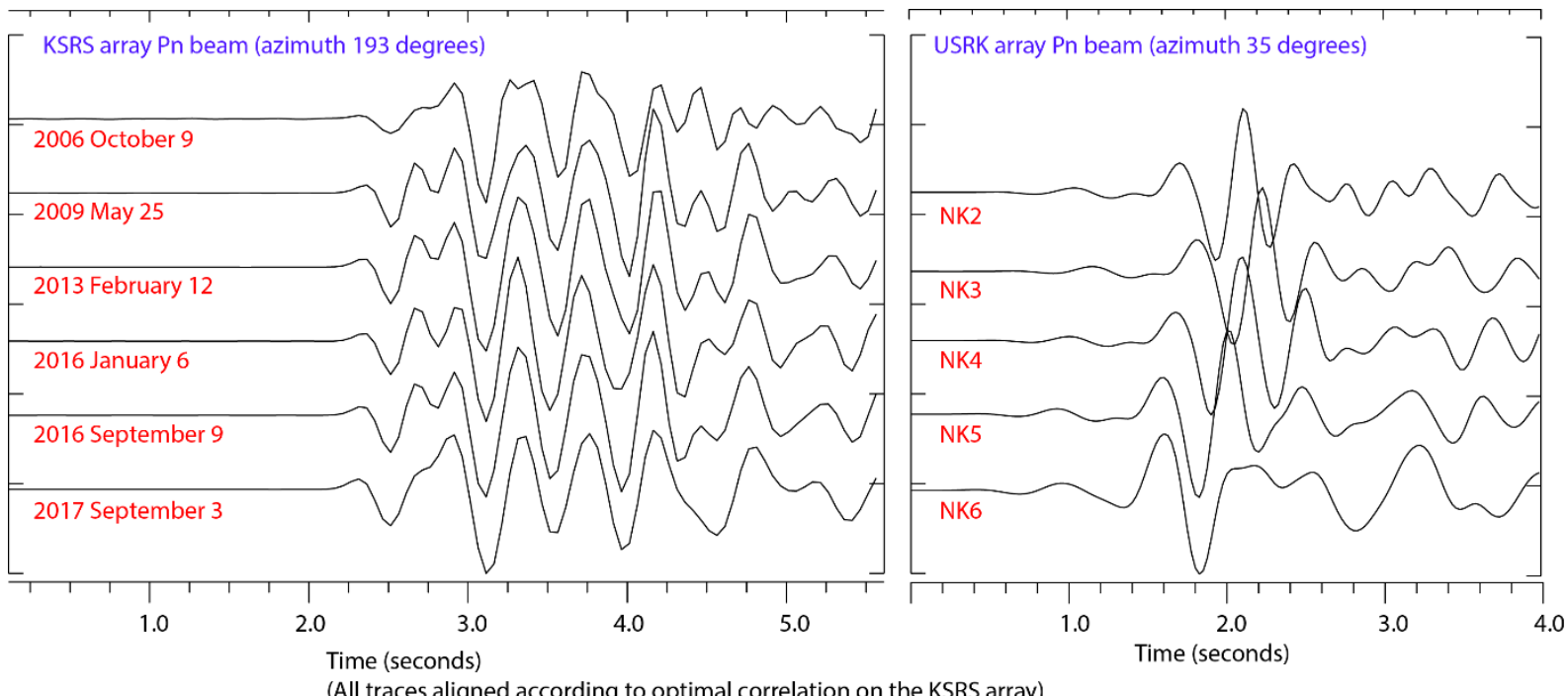

Figure 1. Beams optimized for the Pn arrivals at the International Monitoring System seismic arrays KSRS (Republic of Korea) and USRK (Russian Federation). Identical time-shifts are applied to the traces in both panels with the applied delays being calculated to optimize the alignment of the arrivals at KSRS. KSRS is approximately 4 degrees SSW of the test-site and USRK approximately 4 degrees North East by North of the test-site. The further to the right the USRK signal appears, the closer to KSRS and the further from USRK the event is. The beams in both panels are bandpass filtered 1-4 $\mathrm{Hz}$. Here the traces are scaled individually to have the same maximum amplitude. Figure S3 in the supplementary material provides this figure together with a station map.

Figure 1 displays the waveforms from the six declared DPRK nuclear tests between October 2006 and September 2017 recorded on the two closest IMS stations, KSRS and USRK. (Note that the USRK array came online in 2008 and did not record the 2006 event.) Only the seconds surrounding the initial Pn phase arrivals are displayed and, although there are clearly similarities between the signals generated by all events, the 2017 signals show the greatest differences. Gibbons et al. (2017) locate the first five declared underground nuclear explosions (UNEs) by minimizing the differences between relative time-delay measurements and predictions for pairs of phases. In this way, the origin times a potential source of uncertainty - do not need to be solved for. Figure 1 provides a visualization of these time-differentials for one such pair of phases: Pn at KSRS and Pn at USRK. A beam steered with parameters selected to optimize the array gain for the Pn arrival at KSRS was formed for each of the six declared UNEs and an approximate onset time estimate was made for each of the six traces. A common frequency band was identified in which common features dominated the corresponding 
Pre-acceptance postprint: final paper published on https://doi.org/10.1785/0220180116 Probing the DPRK Nuclear Test Site down to Low-Seismic Magnitude:

Seismological Research Letters (2018) 89 (6): 2034-2041,

S. J. Gibbons, T. Kværna, S. P. Näsholm, S. Mykkeltveit

waveforms from the different events. This is a non-trivial task since the signal-to-noise ratio (SNR) typically increases with increasing frequency within the available band for events at these distances. However, with increasing frequency, the waveform is determined by structure and topography at increasingly smaller length scales and the higher frequency signals show far greater dissimilarity between events. The 1-4 Hz band displayed in Figure 1 was deemed to provide an optimal trade-off between SNR and waveform similarity between the six KSRS Pn-beams. Using multiple crosscorrelation calculations between the different beams, followed by an inversion for absolute timedelays (van Decar and Crosson, 1990), a set of epoch times was calculated which best preserved the alignment of the common KSRS beam waveform characteristics.

The right-hand panel of Figure 1 displays the corresponding set of $\mathrm{Pn}$ beams for five of the six events on the USRK array, steered with a backazimuth and apparent velocity chosen to optimize the array gain for these arrivals. The USRK beams are displayed with the same time-delays used to optimize the alignment of the KSRS beams. There should be an approximately linear relationship between the delay of a given waveform feature between two USRK beams in Figure 1 and the difference in the distances between the two events projected onto a great-circle line between the two stations. If $\boldsymbol{s}_{\text {USRK }}$ denotes the slowness vector with which the seismic wavefield leaves the test-site to reach the USRK array, and $\boldsymbol{s}_{\mathrm{KSRS}}$ denotes the slowness vector with which the wavefield leaves the test-site to reach the KSRS array, then the difference between the absolute times of common features in the beams of Figure 1 for events $a$ and $b$ should be given by

$\left(t^{b}{ }_{U S R K}-t^{b}{ }_{K S R S}\right)-\left(t^{a}{ }_{U S R K}-t^{a}{ }_{K S R S}\right)=-\left(\boldsymbol{s}_{\mathrm{USRK}}-\boldsymbol{s}_{\mathrm{KSRS}}\right) \cdot\left(\boldsymbol{r}^{\mathrm{b}}-\boldsymbol{r}^{\mathrm{a}}\right)$

where $\boldsymbol{r}^{\mathrm{b}}$ and $\boldsymbol{r}^{\mathrm{a}}$ are respectively the displacement vectors of the locations of events $a$ and $b$ relative to a reference location on the test-site. Note that since we have delayed the USRK Pn beams using the absolute time-shifts required to align the KSRS Pn beams, the term on the left-hand side of Equation (1) is simply the difference $\tau^{b}-\tau^{a}$ along the time-axis in the right-hand panel of Figure 1 (where $\tau$ denotes a relative rather than absolute time). If a feature on a USRK beam in Figure 1 appears simultaneously for two events, we can say that the two events are approximately equidistant from the arrays USRK and KSRS. If a feature arrives later at USRK for event $b$ than for event $a$ then we conclude that event $b$ is closer to KSRS, and further away from USRK, than event $a$. The fact that USRK and KSRS are approximately on opposite sides of the source-region means that the magnitude of the slowness vector difference $\left(\boldsymbol{s}_{\mathrm{USRK}}-\boldsymbol{s}_{\mathrm{KSRS}}\right)$ is almost a maximum. Note that the right-hand side of Equation (1) is a scalar product between two vector differences and that the time-difference $\tau^{b}-\tau^{a}$ will also vanish if the displacement vector difference is perpendicular to the slowness vector difference.

Figure 2 (left) displays the waveforms for all 6 UNEs recorded at the MJA0 site of the Matsushiro array (MJAR) in Japan. As with the KSRS beams in Figure 1, these waveforms have been carefully aligned using multiple cross-correlation calculations and the inversion procedure of van Decar and Crosson (1990). The right-hand panel of Figure 2 shows waveforms from the NB200 site of the NORSAR array delayed by the time-shifts applied to the MJAO traces. As in Equation (1), if $t^{\mathrm{a}}$ and $t^{\mathrm{b}}$ denote the absolute times of corresponding features in the wavetrains for events $a$ and $b$, then

$\left(t^{b}{ }_{N O A}-t^{b}{ }_{M J A R}\right)-\left(t^{a}{ }_{N O A}-t^{a}{ }_{M J A R}\right)=-\left(\boldsymbol{s}_{\mathrm{NOA}}-\boldsymbol{s}_{\mathrm{MJAR}}\right) \cdot\left(\boldsymbol{r}^{\mathrm{b}}-\boldsymbol{r}^{\mathrm{a}}\right)$ 
Pre-acceptance postprint: final paper published on https://doi.org/10.1785/0220180116 Probing the DPRK Nuclear Test Site down to Low-Seismic Magnitude:

Seismological Research Letters (2018) 89 (6): 2034-2041,

S. J. Gibbons, T. Kværna, S. P. Näsholm, S. Mykkeltveit

where $\boldsymbol{s}_{\mathrm{NOA}}$ and $\boldsymbol{s}_{\text {MJAR }}$ denote respectively the slowness vectors of the wavefronts leaving the test-site which are ultimately recorded on the NOA and MJAR arrays. The time-moveout of the NOA waveforms is smaller than for the USRK waveforms, and this is because the NOA array is at a teleseismic distance from the DPRK test-site. The seismic waves leaving the source region dive down at a steep angle and the associated wavefront appears to cross the ground at the source more rapidly. In both figures 2 and 3 , it is difficult to discern a moveout in either direction between events NK5 and NK6 - while the moveouts between other event pairs are clear.

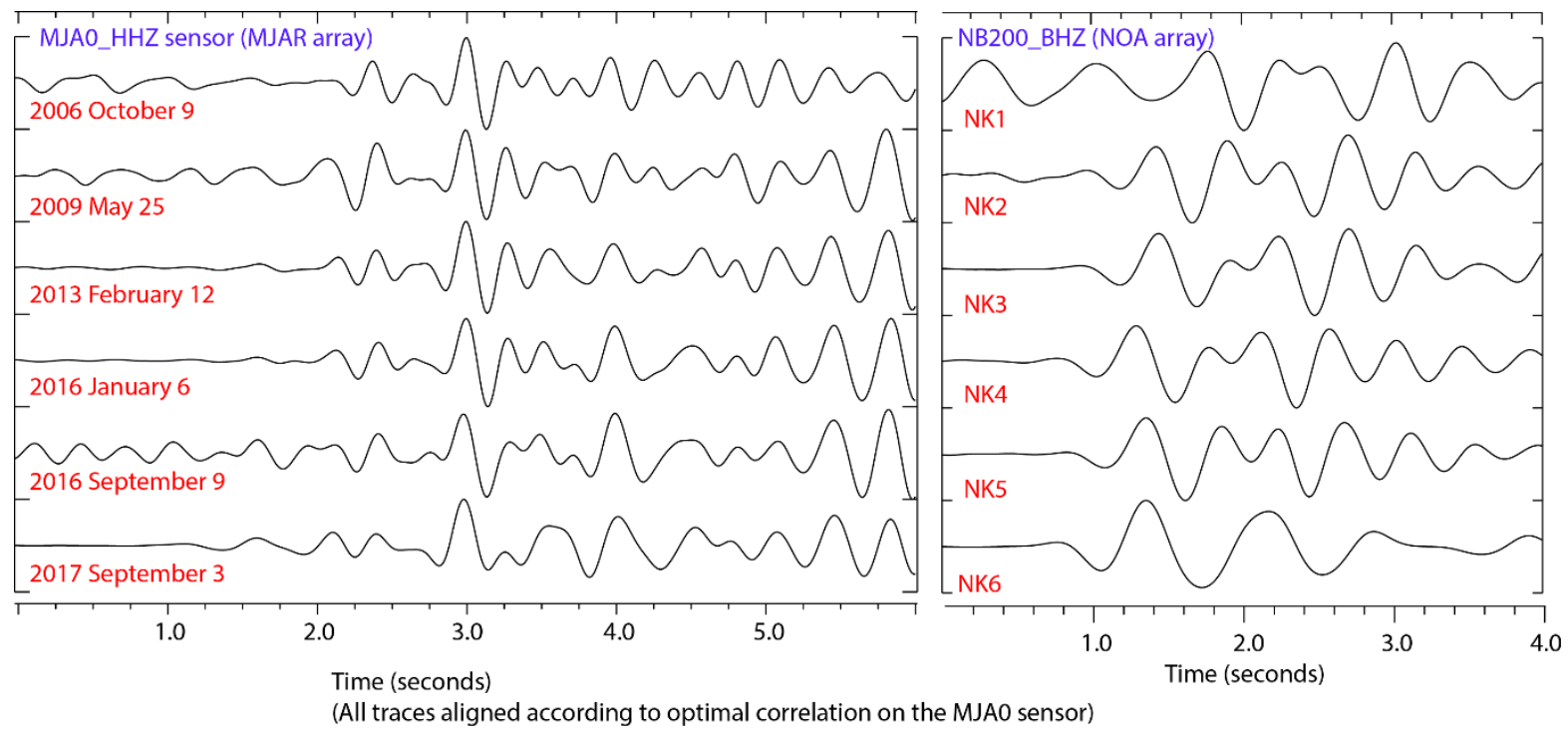

Figure 2 Waveforms for channel MJAO_HHZ of the MJAR array (Japan) and channel NB200_BHZ of the NOA array (Norway). As in Figure 1, the time-shifts applied to the events are identical in left and right panels - fixed to optimize the alignment of the signals in Japan. The frequency band 1.53.5 Hz is applied to all waveforms. The traces are scaled individually to have the same maximum amplitude. Figure $\$ 4$ in the supplementary material provides this figure together with a station map.

The consistency of the time-delays observed in figures 1 and 2 with the existing relative event location estimates is a good test - both of the accuracy of the time-delay estimates and of the quality of our assumed relative positions for NK1 to NK5. A consequence of equations (1) and (2) is that we should be able to lay out a set of parallel lines, with the spacings directly proportional to the timedelays for any given pair of phases, over our relative event locations such that each line passes through the corresponding relative epicenter. This should apply for all pairs of phases. For each phase pair, and corresponding vector of relative time-delays, there should be a unique stretching and rotation of these parallel lines such that every line passes through the correct relative epicenter. The stretching and rotation is specified explicitly by the slowness vector difference ( $\left.\boldsymbol{s}_{\text {PHASE1 }}-\boldsymbol{s}_{\text {PHASE2}}\right)$. If, for a given phase pair, a line does not pass through the corresponding relative location estimate then either the location estimate is wrong, the time-delay measurement is erroneous, or both.

Figure 3 displays the relative location estimates for NK1 to NK5 provided by Gibbons et al. (2017), together with the sets of parallel lines corresponding to the time-delays displayed in Figures 1 and 2. The colored lines correspond to the time-delays estimated for common features in the waveforms in the right-hand panels of figures 1 and 2 and, for both pairs of phases (MJAR-NOA and KSRS-USRK), each line falls approximately over the corresponding location estimate for the first five events. The two waveform panels in Figure 3 show a close-up of the panels in figures 1 and 2 . The time-scale has 
Pre-acceptance postprint: final paper published on https://doi.org/10.1785/0220180116

Probing the DPRK Nuclear Test Site down to Low-Seismic Magnitude:

Seismological Research Letters (2018) 89 (6): 2034-2041,

S. J. Gibbons, T. Kværna, S. P. Näsholm, S. Mykkeltveit

160 been omitted from these close-up images deliberately to help indicate how accurately the placement

161 of the vertical lines represents the relative delays between common features of the waveforms.

162 Given significant waveform dissimilarity, a manual alignment of common features in these

163 seismograms may be as accurate as a time-delay measured by a cross-correlation calculation (see

164 Fisk, 2002). A brief inspection of the right-hand panels of figures 1 and 2 indicates how many cycles

165 could be used to calculate a correlation function. The time-bandwidth product is low and any

166 attempt to improve the time-bandwidth product by filtering to higher frequencies may result in an

167 erroneous time-delay estimate due to increasing waveform incoherence. The black arrows on the

168 seismograms in Figure 3 are transformed onto the map, oriented towards the arrays as labelled. The

169 length and direction of each arrow is in accordance with the difference between the corresponding

170 slowness vectors.

171 The margins by which some of the colored lines in Figure 3 miss the corresponding colored stars is

172 small compared with the distances between the relative epicenter estimates. The display provides

173 validation for the existing relative location estimates. In both waveform panels in Figure 3, the dark

174 blue lines, for event NK6, fall very close to the red lines, for event NK5. The epicenter of NK6 is likely

175 to be very close to that for NK5. A visual way of evaluating alternative location hypotheses for event

176 NK6 is to mark a point on the map, determine where along the USRK or NOA vector the point falls,

177 and then draw a vertical bar onto the seismograms with the corresponding time-delay. Is the line you

178 have drawn consistent with the moveout of the waveforms?

179

180

181

182

183

184 
Pre-acceptance postprint: final paper published on https://doi.org/10.1785/0220180116 Probing the DPRK Nuclear Test Site down to Low-Seismic Magnitude:

Seismological Research Letters (2018) 89 (6): 2034-2041,

S. J. Gibbons, T. Kværna, S. P. Näsholm, S. Mykkeltveit
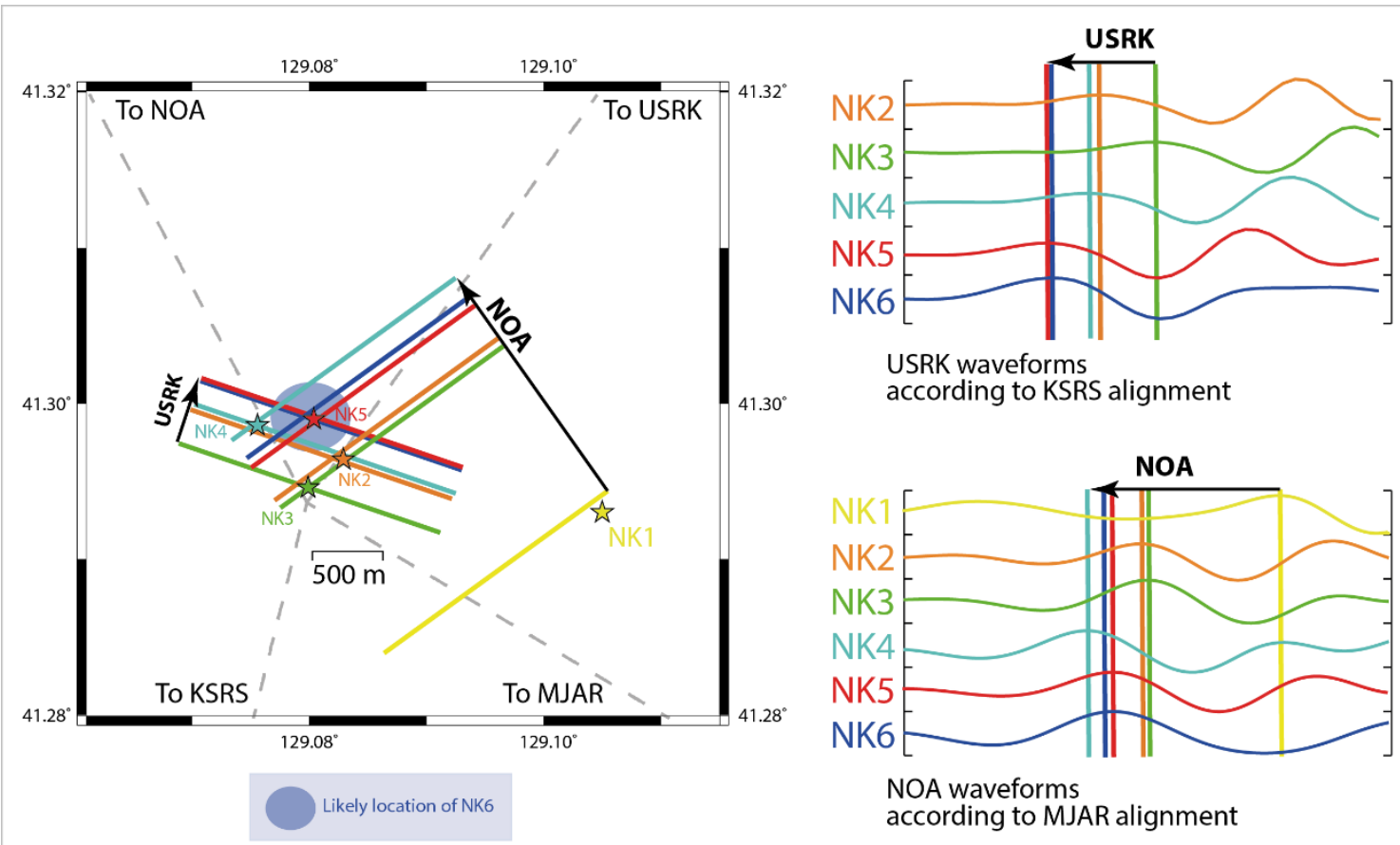

Figure 3 Location estimates for the first five declared nuclear tests as provided by Gibbons et al. (2017) together with the directions to the arrays MJAR, KSRS, USRK and NOA. The vertical colored lines in the waveform panels to the right have been placed as accurately as possible on common waveform features when delayed to optimize the alignment on a station in approximately the opposite direction (figures 1 and 2). The lines are then lifted off the seismograms, stretched and rotated to best fit the fixed location estimates for the first five DPRK nuclear events, but preserving the time-delay relations for both station pairs. The dark blue symbol (partly hidden behind the red symbol for NK5) is drawn where the lines for the 3 September 2017 event cross. Figure S5 in the supplementary material shows an absolute anchoring more consistent with a tunnel-map provided by the DPRK (38 North, 2018). CLOSE TO THE PUNGGYE-RI NUCLEAR TEST-SITE

In addition to the presumed collapse events following NK5 and NK6, numerous small magnitude seismic events have been detected on or close to the test-site. Two such events were detected on 23 September 2017, almost three weeks after NK6. One event at 04.42.57 UT, with a body wave magnitude 2.7, and one at 08.29.14 UT, with a body wave magnitude 3.3, caused considerable media attention with speculation of subsequent testing activity. A visual inspection of the seismic signals indicates greater similarity with the 3 September 2017 collapse event than with any of the declared nuclear tests. Whereas the signal energy for the UNEs is dominated by the P-waves, the energy for the collapse event - and for the two events on September 23 - is dominated by the Lg part of the wavetrain. At time 16.41.06 UT on 12 October 2017, a similar event was recorded with body wave magnitude below 3. The suite of correlation detectors used to monitor the test-site (Gibbons and Ringdal, 2006) was expanded to include templates from these newer events with non-explosion like characteristics. For every event, explosion or not, a P-wave template and an S-wave template was formed - for both USRK and KSRS arrays - and run on near-real-time incoming data from these 
Pre-acceptance postprint: final paper published on https://doi.org/10.1785/0220180116 Probing the DPRK Nuclear Test Site down to Low-Seismic Magnitude:

Seismological Research Letters (2018) 89 (6): 2034-2041,

S. J. Gibbons, T. Kværna, S. P. Näsholm, S. Mykkeltveit

stations. In addition, for the larger events (the UNEs), a regional Pn correlation detector is run on the MJAR array (Japan) and a teleseismic P-wave correlation detector run on the 42-site, large aperture, NORSAR (NOA) array.

For events below magnitude 4, the likelihood of detection using a matched filter (or correlation) detector is highest for the two arrays at regional distances: USRK and KSRS. The SNR for an event at the test-site is typically significantly better at USRK than at KSRS, although KSRS has more sensors than USRK (19 as opposed to 9) which compensates somewhat in improved noise suppression for multi-channel correlation detectors. Gibbons and Ringdal (2012) provide a summary of the significant qualitative differences between the USRK and KSRS waveforms, despite the similar epicentral distances. The path to USRK is continental and high amplitude Pg and Lg phases can be observed. The USRK Sn arrival is difficult to discern. The path to KSRS is partly oceanic and the only clearly visible phases are Pn and Sn, with the Pg and Lg phases being largely blocked.

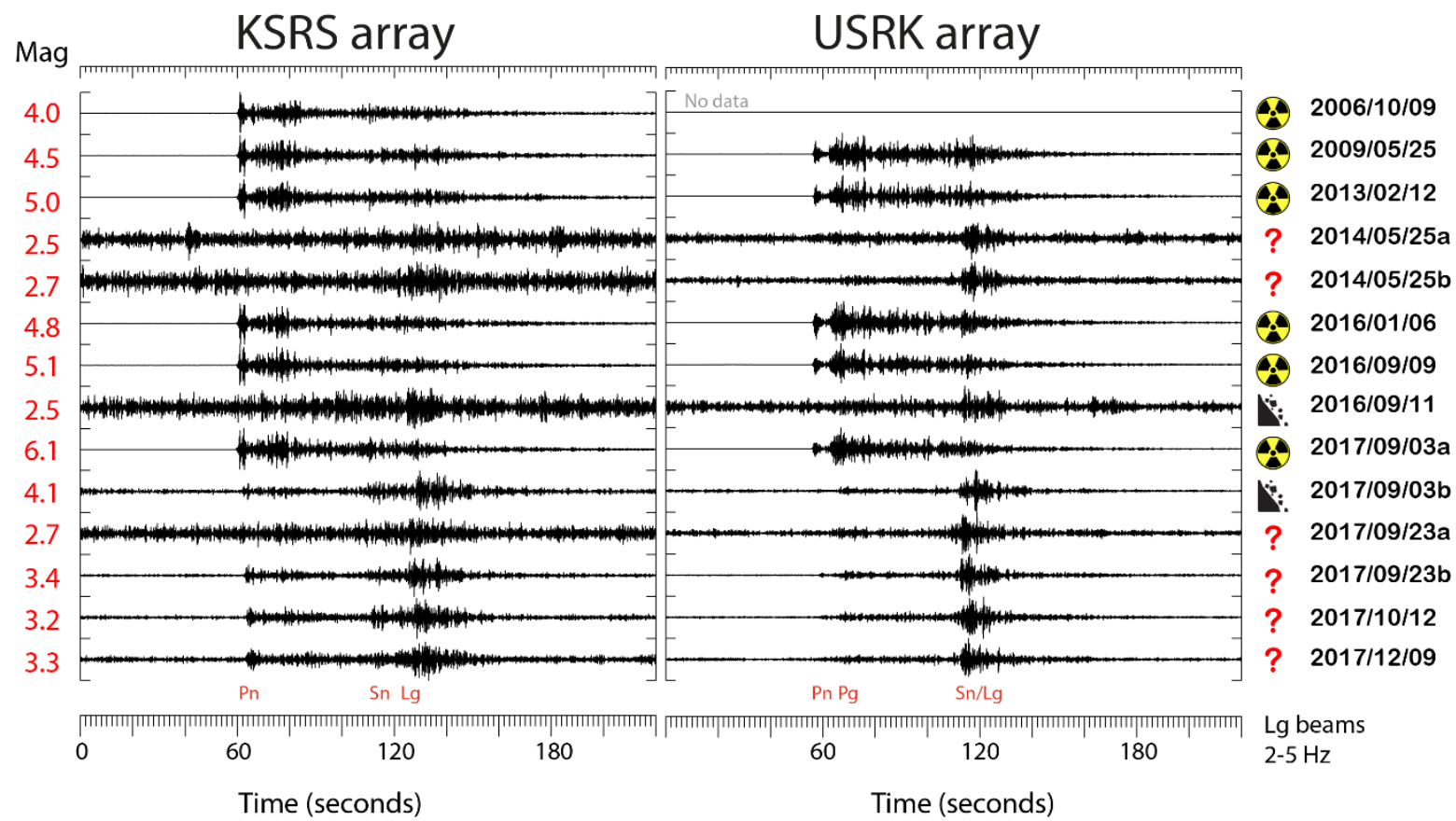

Figure 4 Short-period vertical beams for the KSRS and USRK arrays as indicated for all the declared nuclear tests and some of the largest additional seismic events located at, or close to the test-site, optimized for $\mathrm{Lg}$ with an apparent velocity of $3.5 \mathrm{~km} / \mathrm{s}$. The declared tests are labelled with radioactivity symbols and the two events labelled with "falling rock" symbols are assumed collapses. The remaining events are labelled with question marks. They are clearly at or near the test-site but they do not show characteristics of the declared explosions and the waveform similarity between these events and the nuclear tests is too poor to perform a relative location estimate. KSRS revealed a number of detections both with and without accompanying signals visible above the background noise levels. All of the template events were detected trivially but, in addition, two events on 25 May 2014, at times 06.01.28 UT and 06.43.04 UT, as well as numerous events from and following December 2017. Figure 4 displays beams (aimed at optimizing the Lg signals for both 
Pre-acceptance postprint: final paper published on https://doi.org/10.1785/0220180116 Probing the DPRK Nuclear Test Site down to Low-Seismic Magnitude:

Seismological Research Letters (2018) 89 (6): 2034-2041,

S. J. Gibbons, T. Kværna, S. P. Näsholm, S. Mykkeltveit

arrays) for the events with the largest amplitude signals up to and including 9 December 2017. All available UNE signals are displayed together with the largest of the presumed collapse events and the subsequent events which have become referred to as "aftershocks". The UNE signals are easily distinguished visually from the remaining events given that the $\mathrm{Pn}$ arrival and coda dominates the UNE signals whereas the Lg phase and coda dominates all other signals. The two events in 2014 as also dominated by Lg energy. The exact nature of these events is as yet unknown; the fact that they occurred on the $5^{\text {th }}$ anniversary of the May 2009 UNE (NK2) is likely a coincidence.

In Figure 5 we see a summary of the event-to-event cross-correlation for the Lg part of the signal. Dark colors indicate that the Lg phases of the two events show a high degree of similarity and pale colors indicate little similarity. It is important to remember that the maximum cross-correlation coefficient obtained between two time-series is influenced by a number of factors. Firstly, there is the variation in the Greens functions resulting from differences in the source location and path. Secondly is the difference in the source mechanism; a collapse event, or movement on a fault induced by stress changes within the mountain, will generate a radiation pattern which differs from that of an explosion. In addition, we know that surface reflections will result in so-called depth phases which will influence the shape of the event coda (see, e.g. Douglas, 2013, for an overview). The signals from very shallow events are influenced very early on in the coda by the depth phases since the traveltime between the source location and the reflecting surface is exceptionally short for the events considered here. Differences in the signal deformation due to free surface reflections from one event to another will decrease the waveform similarity and may degrade or even invalidate correlation measurements of delay-times. Significantly, since the North Korean tests are taking place in mountains with steep-sided topography, these surface reflections will be governed by small differences in source location relative to a surface with rapidly changing 3-dimensional geometry. This will lead to significant azimuthal differences in the outgoing wavefield (e.g. Frankel and Leith, 1992) and is most likely the dominant cause of the differences in waveform similarity between the 2006 and 2009 events observed at different azimuths (Gibbons et al. 2017). Finally is the difference in the size of the source. This will affect the signal in different ways, with the SNR and the dominant frequency being the most obvious functions of the event magnitude. However, the excitation of different frequencies changes with the source dimensions and, even in a relatively narrow filter band, the different source spectra may make waveforms differ significantly.

Clear clusters are observed in both correlation grids in Figure 5. For the KSRS array, there are essentially three clusters: one consisting of the five declared UNEs between May 2009 and September 2017, one consisting of the recent non-explosion-like events from the fall of 2017, and one consisting of the two small events from 25 May 2014. The other events, the 2006 declared nuclear explosion (NK1) and the two presumed collapse events following NK5 and NK6, do not correlate closely with any other events. On the USRK array, there are essentially two clusters - the declared UNEs and a single cluster containing the events from May 2014 and the fall of 2017. The correlation matrices in Figure 5 provide us with a warning against overinterpretation of correlation values on a single station. The correlations between the 2014 and fall 2017 events on USRK give the impression of great waveform similarity whereas the corresponding calculations on the KSRS array do not. The SNR for all events is better on USRK than on KSRS, and the larger amplitude Lg phase is clearly visible on the USRK waveforms but not on the KSRS waveforms. The lack of similarity between 2014 and 2017 events cannot however simply be a result of lower SNR since the two events in May 2014 correlate well with each other at KSRS. 
283 The 11 September 2016 event resembles more the non-explosive sources in the waveform plots (Figure 4) but correlates more closely with the UNE signals in the USRK panel of Figure 5 (see the electronic supplement for additional details). For the KSRS recordings, the 11 September signal correlates very poorly with all of the nuclear explosion signals and the only marginal waveform likeness is between this signal and that from the 2014 events. The collapse event on 3 September 2017 shows marginal similarity only to the NK6 UNE signal on KSRS. On USRK, the correlation for the Lg waveform segment is poor between these two events. Note that the matrices displayed in Figure S7 are functions of the frequency band selected and the data window specified. Changing any of these parameters will change the significance of the different factors controlling the waveform similarity. The waveform similarity between the 11 September 2016 USRK signal and the corresponding signal for NK5 displayed in Figure $\mathrm{S} 6$ in the electronic supplement cannot be reproduced for the KSRS array. This may be due to the correlation at USRK being dominated by the Lg phase and the correlation at KSRS being dominated by the Sn phase. The electronic supplement also contains a demonstration of detecting a rapid sequence of small events close to the test-site and a list of clear detections up to and including the end of 2017. 

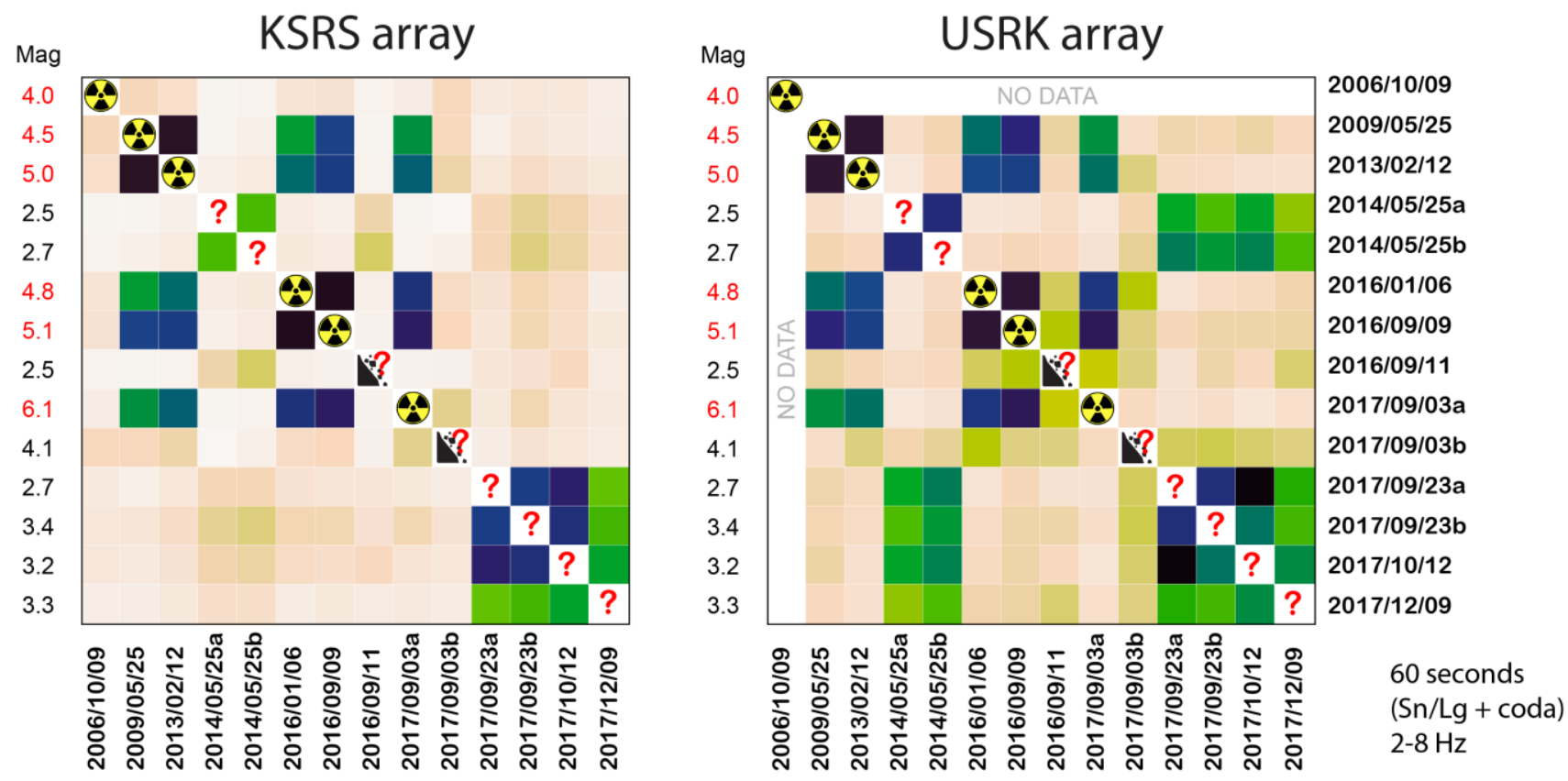

Correlation Coef.

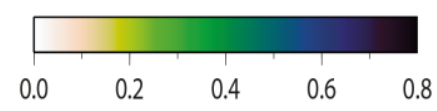

300 Figure 5. Correlation matrices for 60-second-long multichannel templates for the Sn and Lg parts of the wavetrains at KSRS and USRK. Instead of the trivial unit correlation values, the diagonal elements indicate the source-type identification symbol for each event. Declared nuclear test explosions are labelled with a radioactivity symbol, presumed collapse events are labelled with a rockfall symbol and question mark, and the events of unknown origin are labelled with question marks only. 
Pre-acceptance postprint: final paper published on https://doi.org/10.1785/0220180116 Probing the DPRK Nuclear Test Site down to Low-Seismic Magnitude:

Seismological Research Letters (2018) 89 (6): 2034-2041,

S. J. Gibbons, T. Kværna, S. P. Näsholm, S. Mykkeltveit

306

307

308

309

310

311

312

313

314

315

316

317

318

319

320

321

322

323

324

325

326

327

328

329

330

331

\section{CONCLUSIONS}

The 3 September 2017 underground nuclear explosion (NK6) at the Punggye-ri test-site in North Korea was by far the largest declared test at this site. Locating this event using classical double difference procedures is challenging since we need to consider lower frequencies with correspondingly larger uncertainties in the time-delay measurements. By carefully aligning all available UNE signals at one station, and measuring as accurately as possible the time-shifts at a station on the opposite side of the test-site, we can demonstrate geometrically - using existing relative location estimates for the previous UNEs as fixed points - that NK6 took place very close to the previous test on 9 September 2016.

We demonstrate that multi-channel correlation detectors, using long duration templates at the USRK and KSRS seismic arrays, can detect signals somewhat below magnitude 2 at, or very close to, the test-site. Signal templates for P/P-coda and S/S-coda (including Lg) were run for all well-observed events and events at or close to the test-site are typically detected by many different templates. The explosions are detected most confidently using the P-signal templates and the presumed earthquakes are detected most confidently using the S-signal templates. This is likely a function of both source mechanism and the SNR of those parts of the wavetrain.

Numerous events with non-explosion like characteristics were detected following NK6 and these detections have continued into 2018. A small number of similar events were also detected prior to NK6 suggesting that these earthquake-like events have a more complicated explanation than simple rock-failure in the immediate vicinity of the 2017 explosion. The waveform similarity between the signals from the underground nuclear explosions and these additional events is too poor to be able to locate the events relative to the test-site infrastructure. We present a study of waveform similarity between the different events detected using the USRK and KSRS arrays and note that there are some significant differences between the observations at the two arrays. This suggests that the differences in azimuth, and in the propagation characteristics for the regional seismic wavefield, may be as significant as the distances between hypocenters in determining the degree of waveform similarity. 
Pre-acceptance postprint: final paper published on https://doi.org/10.1785/0220180116 Probing the DPRK Nuclear Test Site down to Low-Seismic Magnitude:

Seismological Research Letters (2018) 89 (6): 2034-2041,

S. J. Gibbons, T. Kværna, S. P. Näsholm, S. Mykkeltveit

332

333

334

335

336

337

338

339

340

341

342

343

\section{DATA AND RESOURCES}

Waveform data from the NOA seismic array is open and available from NORSAR at http://www.norsardata.no/NDC/data/autodrm.html

Data from the USRK, KSRS, and MJAR arrays was obtained from the International Data Center (IDC) of the Comprehensive Nuclear-Test-Ban Treaty Organization (CTBTO) in Vienna. The virtual data exploitation center (VDEC) at the CTBTO may provide a mechanism by which scientists not from National Data Centers can obtain access to the data. https://www.ctbto.org/specials/vdec/

\section{ACKNOWLEDGEMENTS}

All maps generated by the GMT package, Wessel and Smith (1995). 
Pre-acceptance postprint: final paper published on https://doi.org/10.1785/0220180116 Probing the DPRK Nuclear Test Site down to Low-Seismic Magnitude:

Seismological Research Letters (2018) 89 (6): 2034-2041,

S. J. Gibbons, T. Kværna, S. P. Näsholm, S. Mykkeltveit

\section{REFERENCES}

Adushkin, V. V., Bobrov, D. I., Kitov, I. O., Rozhkov, M. V., and Sanina, I. A. (2017), Remote detection of aftershock activity as a new method of seismic monitoring, Doklady Earth Sciences 473, 303-307, doi:10.1134/s1028334x17030011

Douglas, A. (2013), Forensic Seismology and Nuclear Test Bans, Cambridge University Press, Cambridge, ISBN 9781107033948

Fisk, M. D. (2002), Accurate Locations of Nuclear Explosions at the Lop Nor Test Site Using Alignment of Seismograms and IKONOS Satellite Imagery, Bulletin of the Seismological Society of America 92, 2911-2925, doi:10.1785/0120010268

Frankel, A. and W. Leith (1992), Evaluation of topographic effects on P and S-waves of explosions at the northern Novaya Zemlya test site using 3-D numerical simulations, Geophysical Research Letters 19, pp. 1887-1890, doi: 10.1029/92GL02147

Gibbons, S. J. and Ringdal, F. (2006), The detection of low magnitude seismic events using arraybased waveform correlation, Geophysical Journal International 165, 149-166, doi:10.1111/i.1365-246x.2006.02865.x

Gibbons, S. J. and F. Ringdal (2012), Seismic Monitoring of the North Korea Nuclear Test Site Using a Multichannel Correlation Detector, IEEE Transactions of Geoscience and Remote Sensing 50, 1897-1909, doi:10.1109/tgrs.2011.2170429

Gibbons, S. J., Pabian, F., Näsholm, S. P., Kværna, T., and Mykkeltveit, S. (2017), Accurate relative location estimates for the North Korean nuclear tests using empirical slowness corrections, Geophysical Journal International 208, pp. 101-117 http://dx.doi.org/10.1093/gji/ggw379

Liu, J., Li, L., Zahradník, J., Sokos, E., Liu, C., and Tian, X. (2018), North Korea's 2017 test and its non-tectonic aftershock, Geophysical Research Letters, http://dx.doi.org/10.1002/2018GL077095

Rodgers, A.J., Petersson, N.A., Sjogreen, B. (2010), Simulation of topographic effects on seismic waves from shallow explosions near the North Korean nuclear test site with emphasis on shear wave generation, Journal of Geophysical Research, Solid Earth 115, B11309, doi:10.1029/2010jb007707

van Decar, J. C. and Crosson, R. S. (1990), Determination of teleseismic relative phase arrival times using multi-channel cross-correlation and least squares, Bulletin of the Seismological Society of America 80, 150-169.

Wang, T., Shi, Q., Nikkhoo, M., Wei, S., Barbot, S., Dreger, D., Bürgmann, R., Motagh, M., and Chen, Q. (2018), The rise, collapse, and compaction of Mt. Mantap from the 3 September 2017 North Korean nuclear test, Science, doi:10.1126/science.aar7230

Wessel, P. and W. H. F. Smith (1995), New version of the generic mapping tools released, EOS Transactions, American Geophysical Union 76, no. 33, 329, doi:10.1029/98eo00426.

38 North (2018) "Destruction at North Korea's Nuclear Test Site: A Review in Photos ") (https://www.38north.org/2018/05/punggye052518/, last accessed 30 May 2018). 


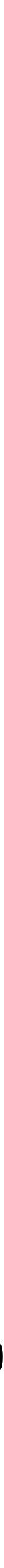




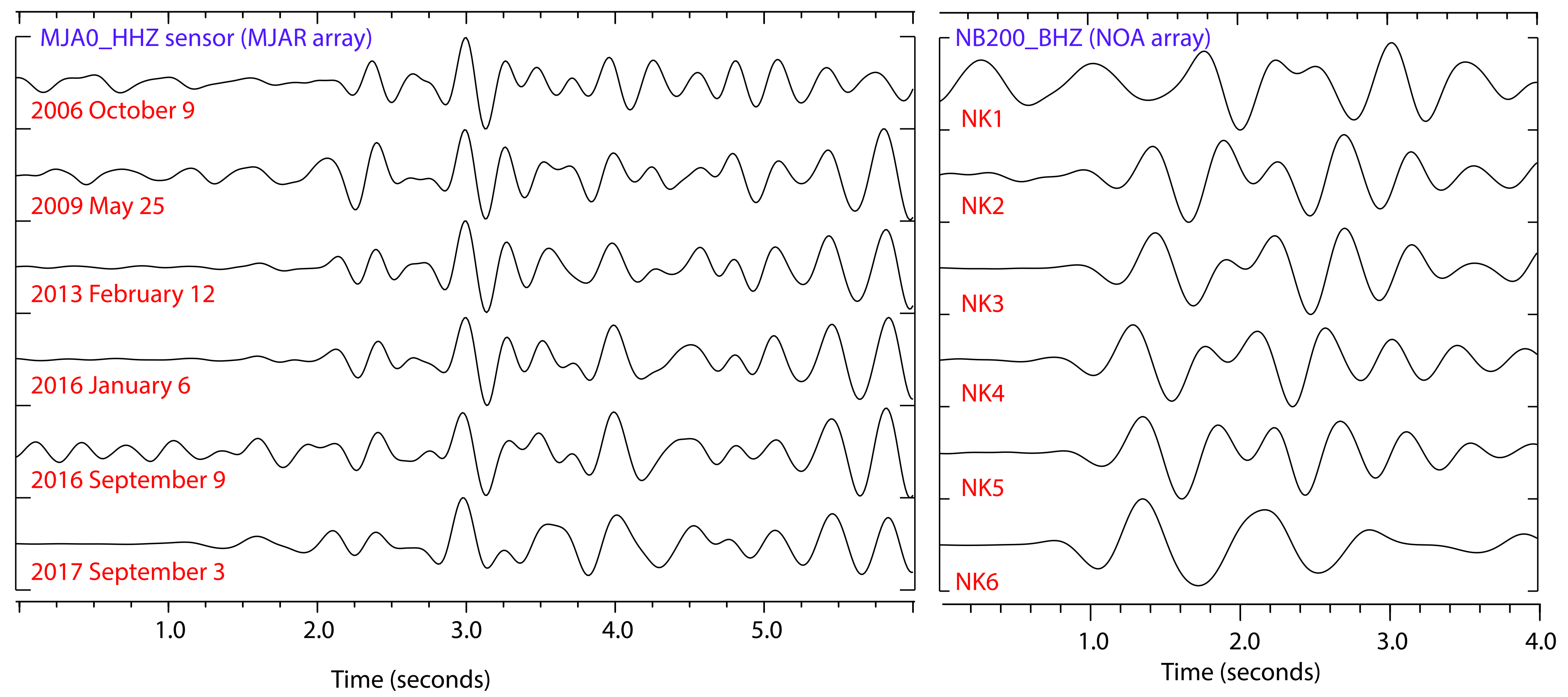

(All traces aligned according to optimal correlation on the MJA0 sensor) 
$129.08^{\circ}$

$129.10^{\circ}$

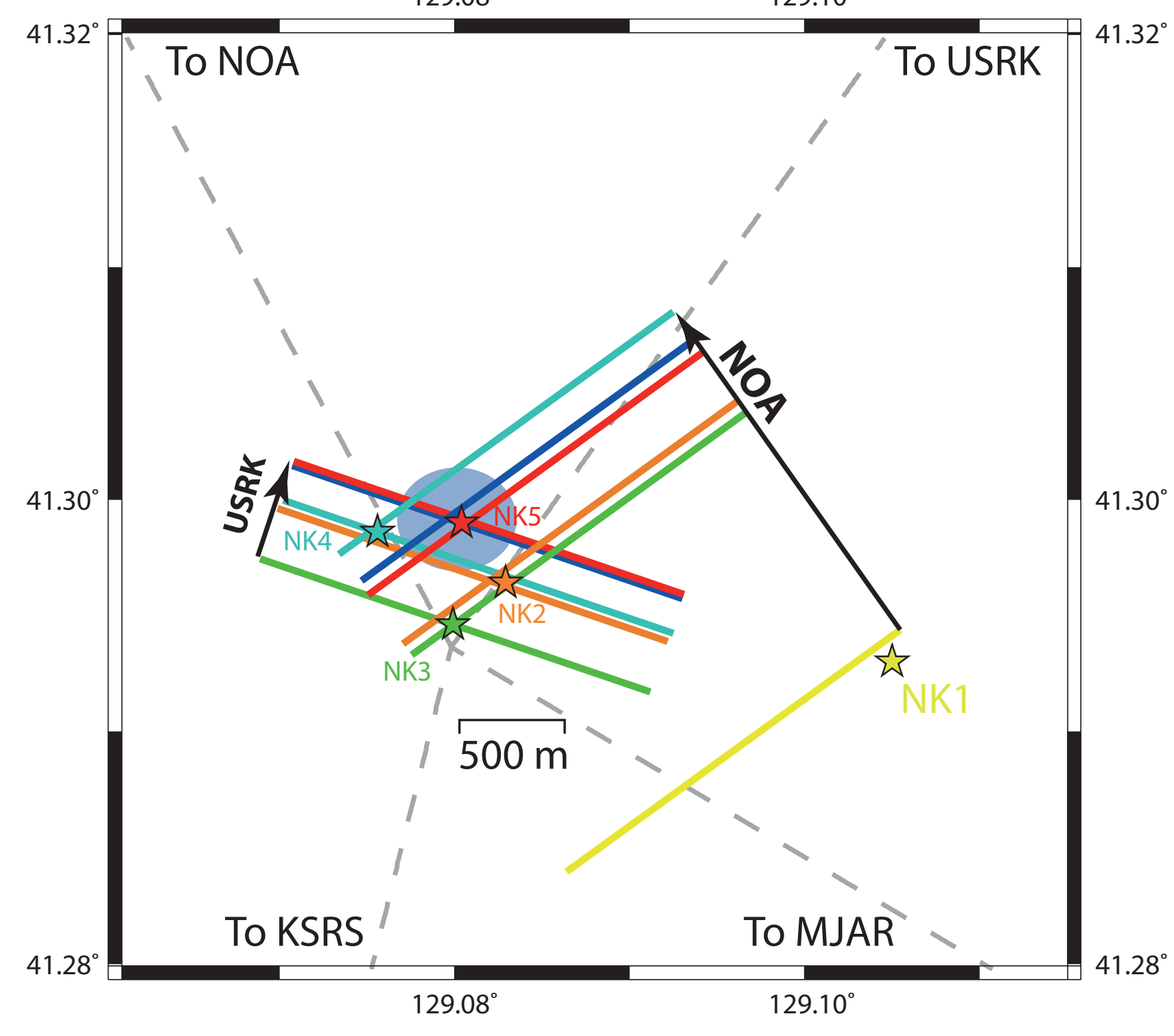

Likely location of NK6

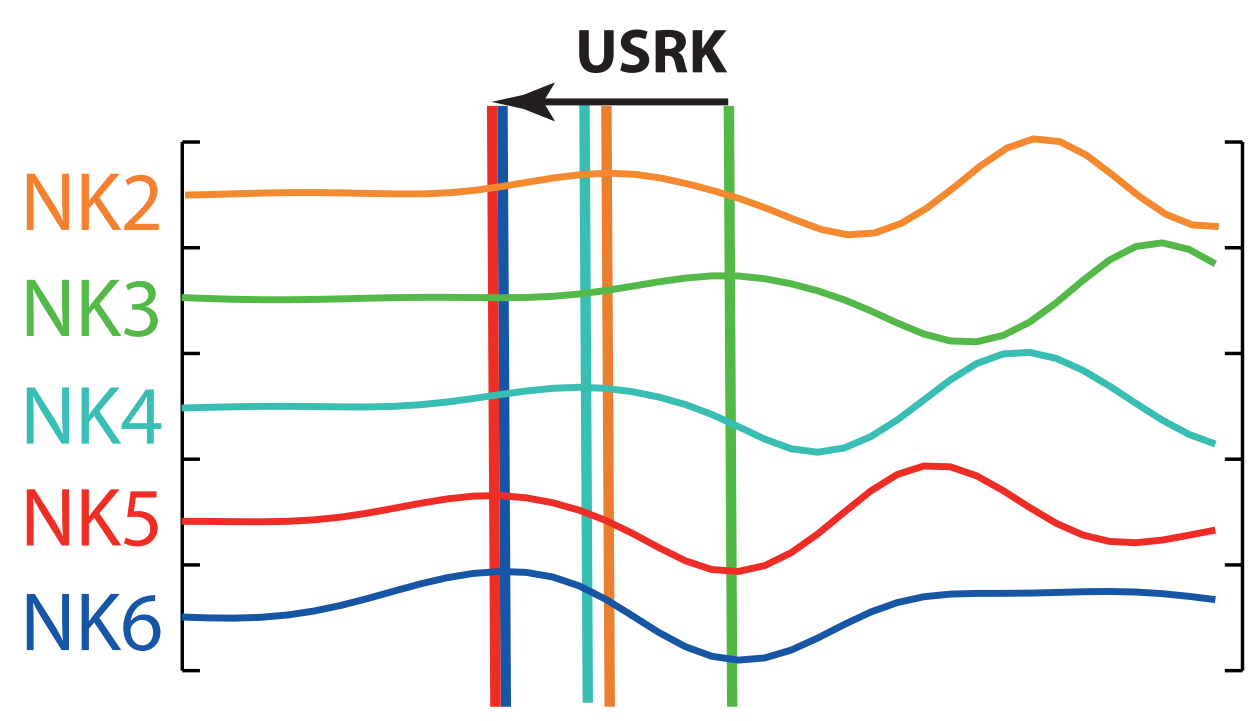

USRK waveforms according to KSRS alignment

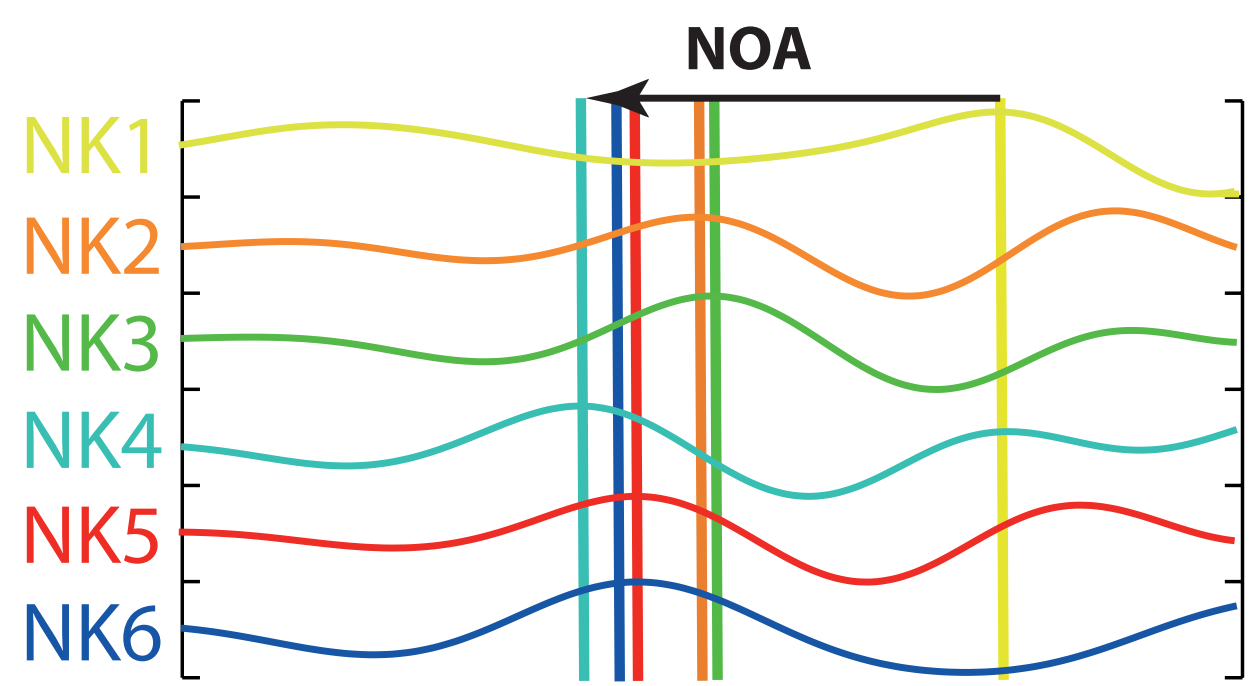

NOA waveforms according to MJAR alignment 
KSRS array

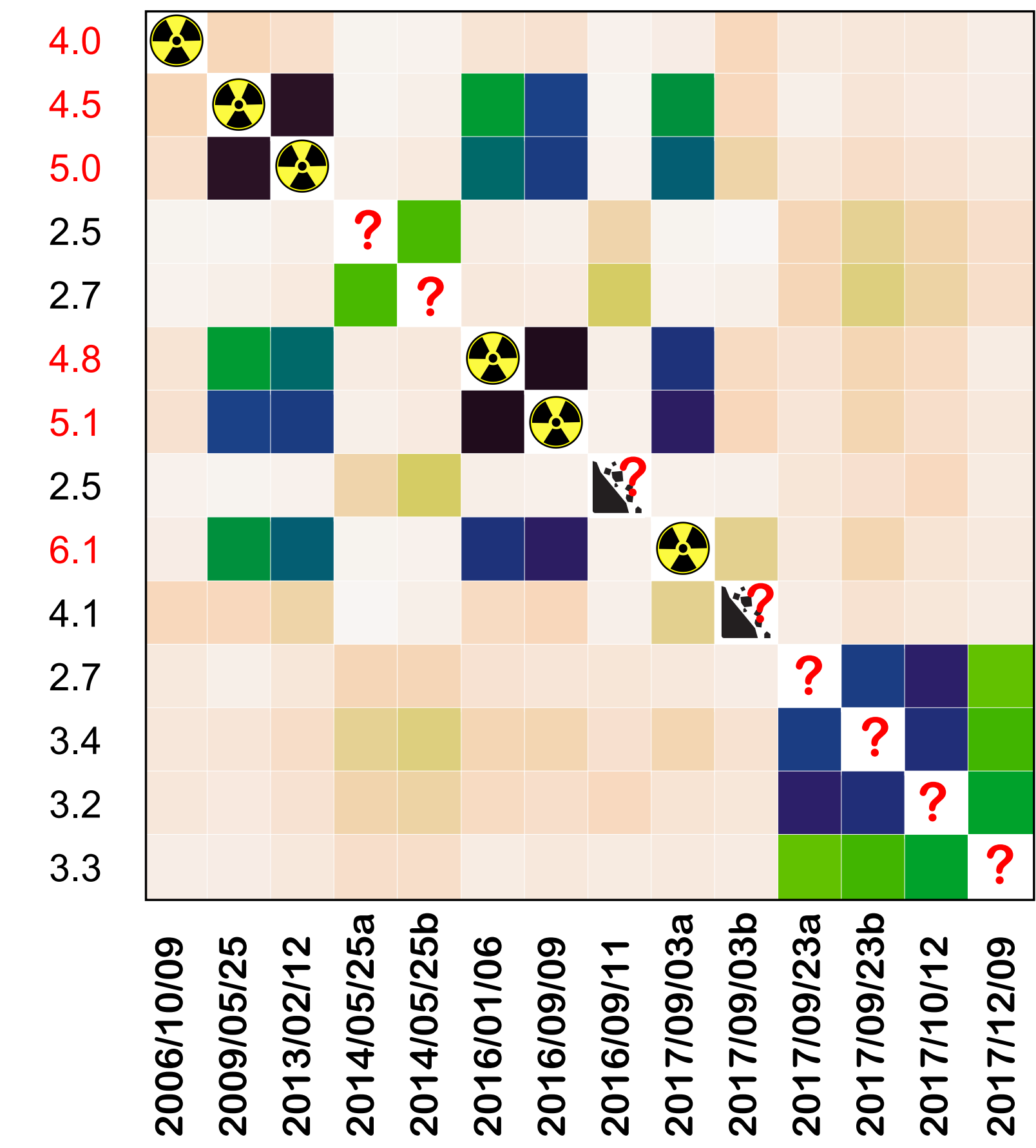

USRK array

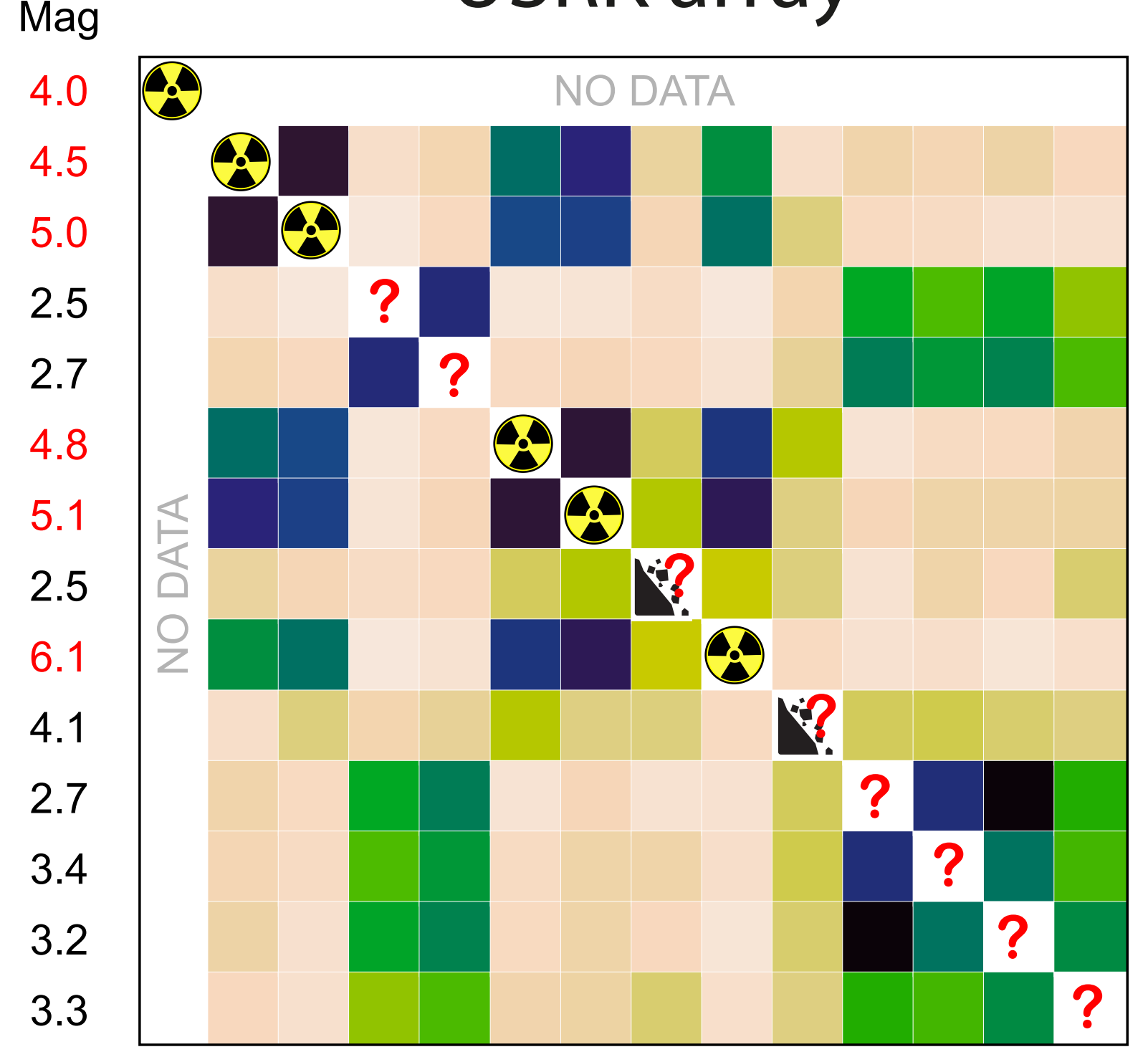

2006/10/09 2009/05/25 2013/02/12 2014/05/25a 2014/05/25b 2016/01/06 2016/09/09 2016/09/11 2017/09/03a 2017/09/03b 2017/09/23a 2017/09/23b 2017/10/12 2017/12/09

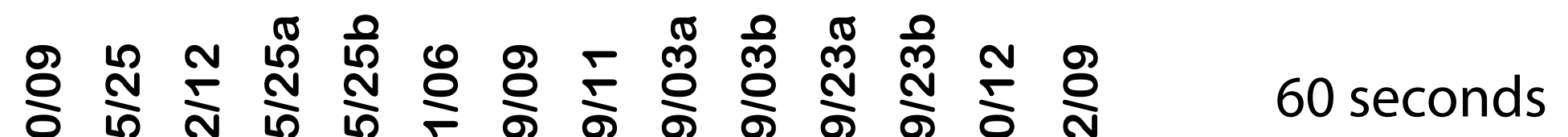

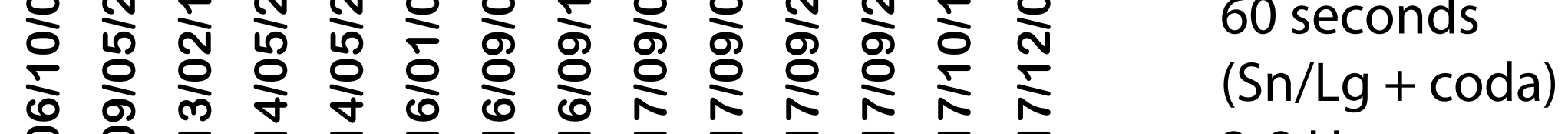
定 穴

Correlation Coef.

$\begin{array}{lllll}0.0 & 0.2 & 0.4 & 0.6 & 0.8\end{array}$


Probing the DPRK Nuclear Test Site down to Low-Seismic Magnitude:

Seismological Research Letters (2018) 89 (6): 2034-2041,

S. J. Gibbons, T. Kværna, S. P. Näsholm, S. Mykkeltveit

\section{Probing the DPRK nuclear test-site down to low seismic magnitude}

\section{Steven J. Gibbons ${ }^{1}$, Tormod Kværna ${ }^{1}$, Sven Peter Näsholm ${ }^{1}$ and Svein Mykkeltveit ${ }^{1}$}

\section{Electronic supplement}

This document contains figures and discussion of relevance to the manuscript "Probing the DPRK nuclear test-site down to low seismic magnitude" submitted to Seismological Research Letters in April 2018.

Figure S1 displays optimal beams on the NORSAR array (NOA) for the 6 declared DPRK nuclear tests.

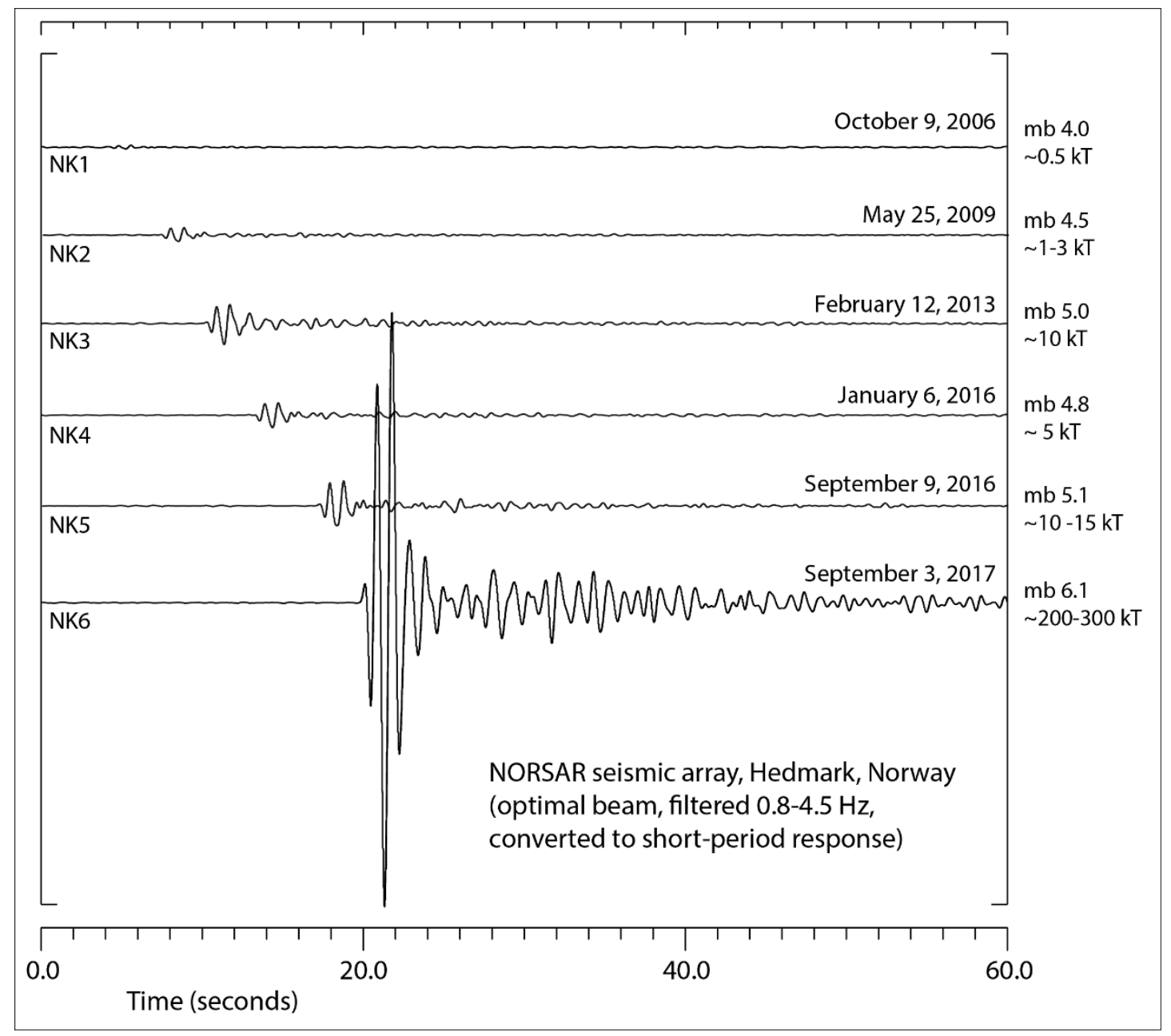

Figure S1. Beams on the NOA (NORSAR) array in Norway with time-shifts optimized for beam-gain of the first P-wave arrival from the DPRK test-site for the six declared nuclear tests up to and including September 3, 2017. All traces are converted to the same short-period response and are all displayed to the same vertical scale. A short time-offset has been applied to each event to ensure the visibility of all arrivals. Figure $\mathbf{S 2}$ displays the same traces aligned and individually scaled to highlight the difficulty in waveform alignment.

\footnotetext{
${ }^{1}$ NORSAR, Kjeller, Norway.
} 
Figure S2 displays a shorter waveform segment of the same traces displayed in Figure S1 but aligned by cross-correlation and scaled individually in amplitude in order that the corresponding features in the waveforms can be compared more easily. Although there are clear similarities between all traces, the differences in the traces mean that if we align one feature to the best of our abilities other features will appear to be misaligned. The correspondence is best for events 2, 3, 4, and 5 . Event 1 has a lower signal-to-noise ratio and the waveform corresponding to Event 6 has far higher energy at low frequency and appears to be "stretched out" in comparison with the previous four signals.

The first signal onset for each trace is of quite low amplitude and picking the exact time at which the signal emerges from the background noise is difficult. The accuracy of correlation-based time-delay estimates exploits the higher amplitudes which come later in the signal. This method works well when the signals are close to identical, but can provide misleading estimates if there are significant dissimilarities in the waveforms. In Figure S2, the large peaks of the NK6 signal are well-aligned with the large peaks of the NK5 signal. However, the signal onset of the NK6 signal appears to arrive sooner than the signal onset of the NK5 signal. A basic cross-correlation calculation may provide a time-delay estimate which is significantly in error.

The reference site of the NOA array is $7359 \mathrm{~km}$ from the assumed location of the September 3, 2017, nuclear test and, assuming the wavefield leaves the test-site according to the ak135 velocity model, the apparent velocity of the outgoing wavefront is $17.3 \mathrm{~km}$ per second. This provides an approximate estimate of the distance uncertainty associated with a given time uncertainty. 
Pre-acceptance postprint: final paper published on https://doi.org/10.1785/0220180116

Probing the DPRK Nuclear Test Site down to Low-Seismic Magnitude:

Seismological Research Letters (2018) 89 (6): 2034-2041,

S. J. Gibbons, T. Kværna, S. P. Näsholm, S. Mykkeltveit

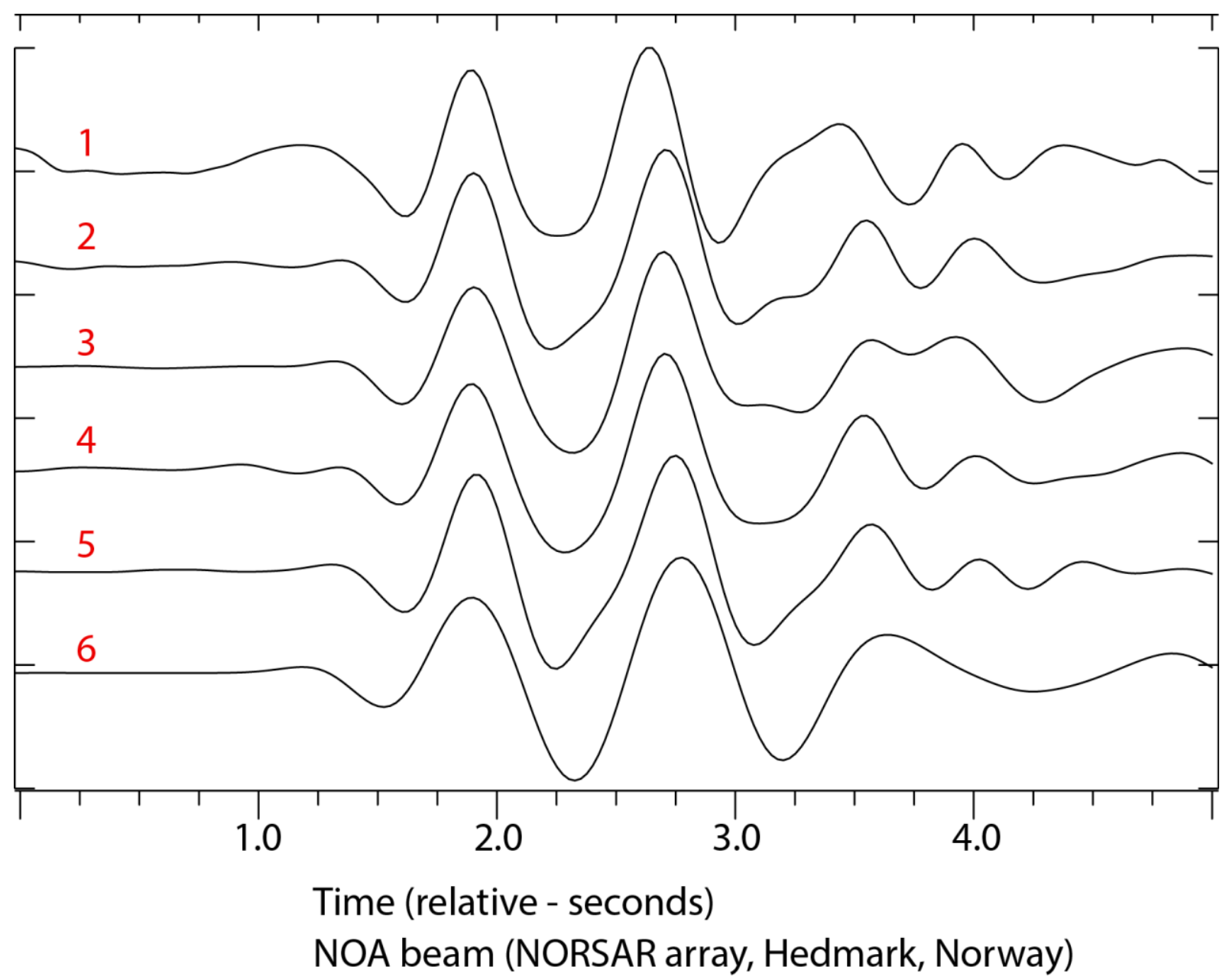

Figure S2. Beams on the NOA (NORSAR) array in Norway with time-shifts between sensors optimized for beam-gain of the first P-wave arrival from the DPRK test-site for the six declared nuclear tests up to and including September 3, 2017. The traces are Butterworth bandpass filtered between 0.8 and $4.5 \mathrm{~Hz}$. All traces are converted to the same short-period response and are scaled individually and aligned according to the maximum correlation coefficients between the different traces.

Figure $\mathrm{S} 3$ is essentially the same as Figure 1 in the paper, but with a map included such that the locations of the receivers can be examined in relation to the source.

Figure $\mathrm{S} 4$ is essentially the same as Figure 2 in the paper, but with a map included such that the locations of the receivers can be examined in relation to the source. 
Pre-acceptance postprint: final paper published on https://doi.org/10.1785/0220180116

Probing the DPRK Nuclear Test Site down to Low-Seismic Magnitude:

Seismological Research Letters (2018) 89 (6): 2034-2041,

S. J. Gibbons, T. Kværna, S. P. Näsholm, S. Mykkeltveit

a)
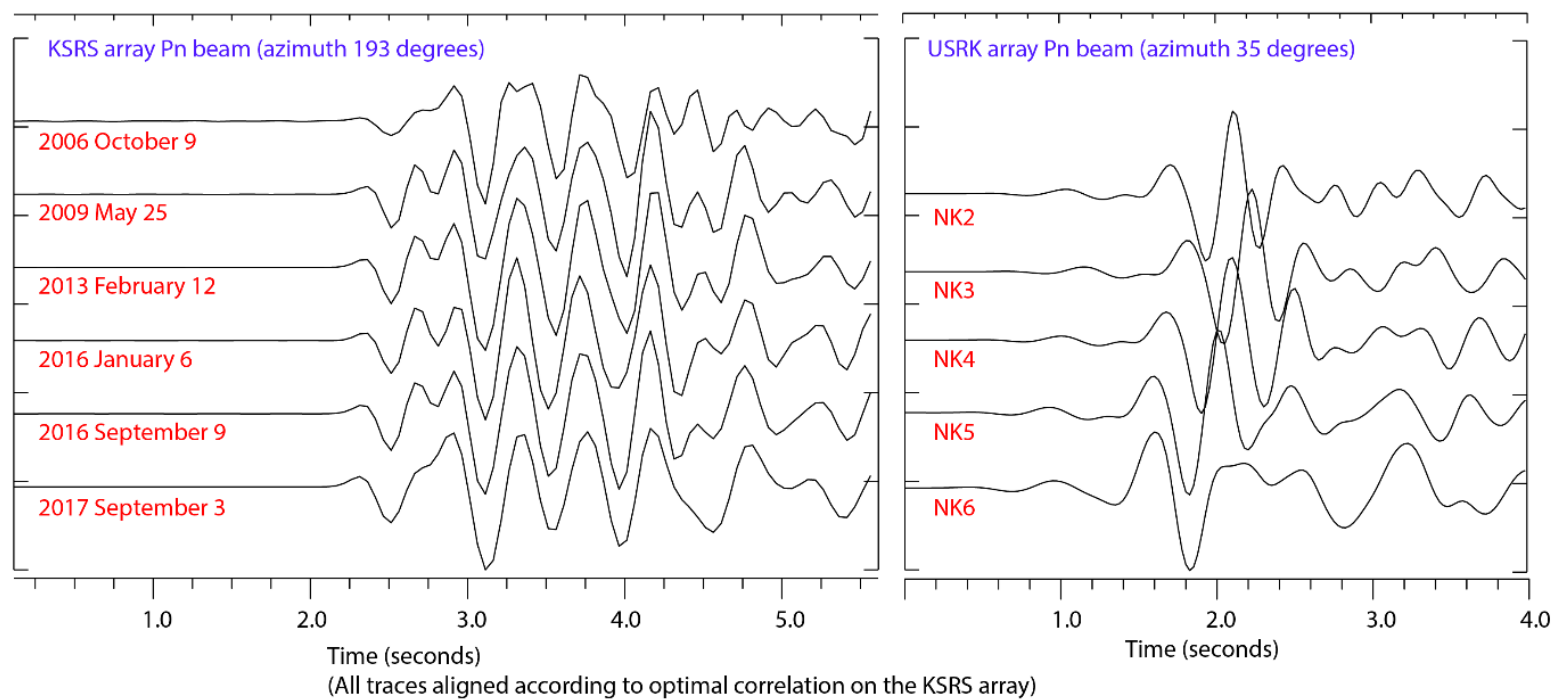

b)

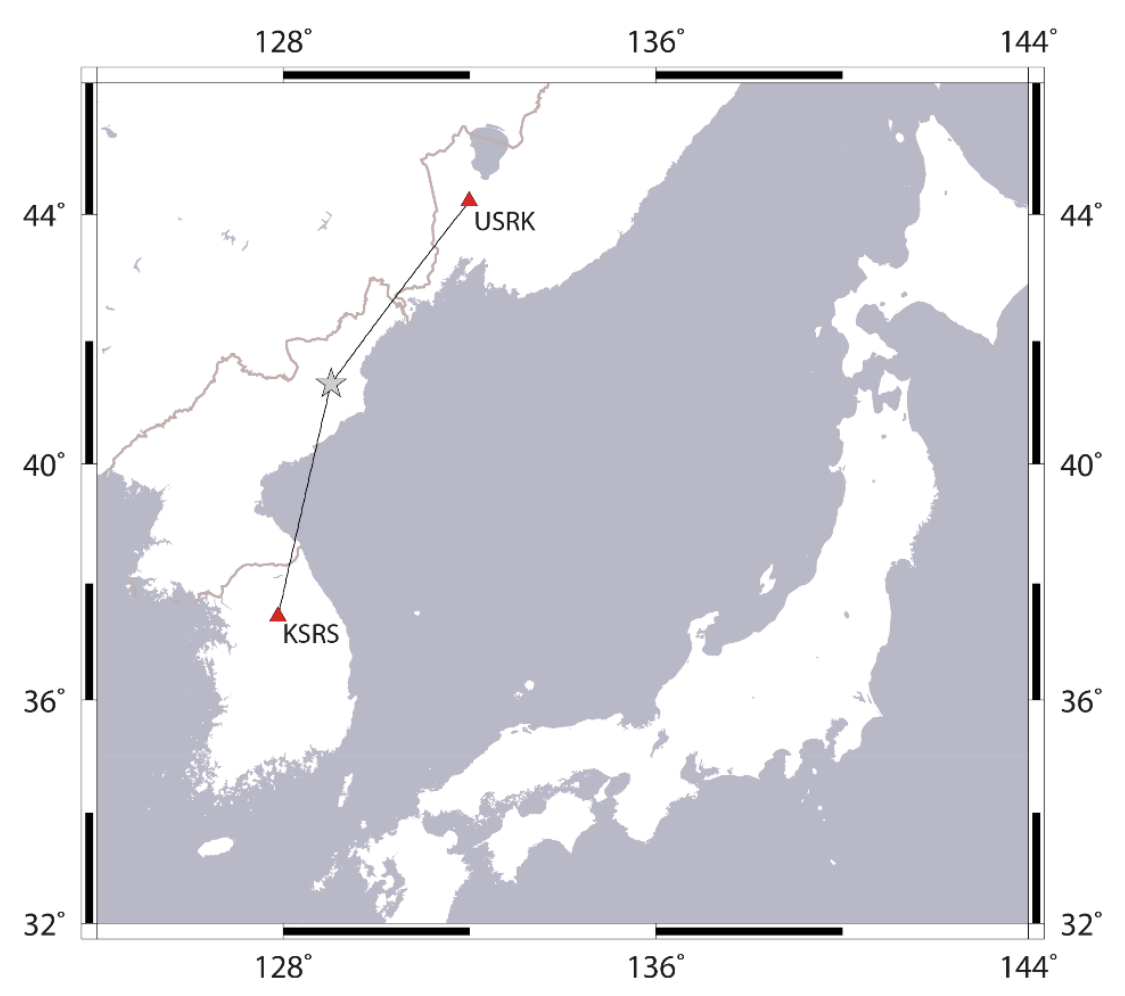

Figure S3 (a) Beams optimized for the Pn arrivals at the International Monitoring System seismic arrays KSRS (Republic of Korea) and USRK (Russian Federation). Identical time-shifts are applied to the traces in both panels with the applied delays being calculated to optimize the alignment of the arrivals at KSRS. KSRS is approximately 4 degrees SSW of the test-site and USRK approximately 4 degrees North East by North of the test-site. The further to the right the USRK signal appears, the closer to KSRS and the further from USRK the event is. The beams in both panels are bandpass filtered 1-4 Hz. Here the traces are scaled individually to have the same maximum amplitude. (b) Map showing locations of the KSRS and USRK seismic arrays in relation to the DPRK test-site (star symbol). 
Pre-acceptance postprint: final paper published on https://doi.org/10.1785/0220180116 Probing the DPRK Nuclear Test Site down to Low-Seismic Magnitude:

Seismological Research Letters (2018) 89 (6): 2034-2041,

S. J. Gibbons, T. Kværna, S. P. Näsholm, S. Mykkeltveit

a)

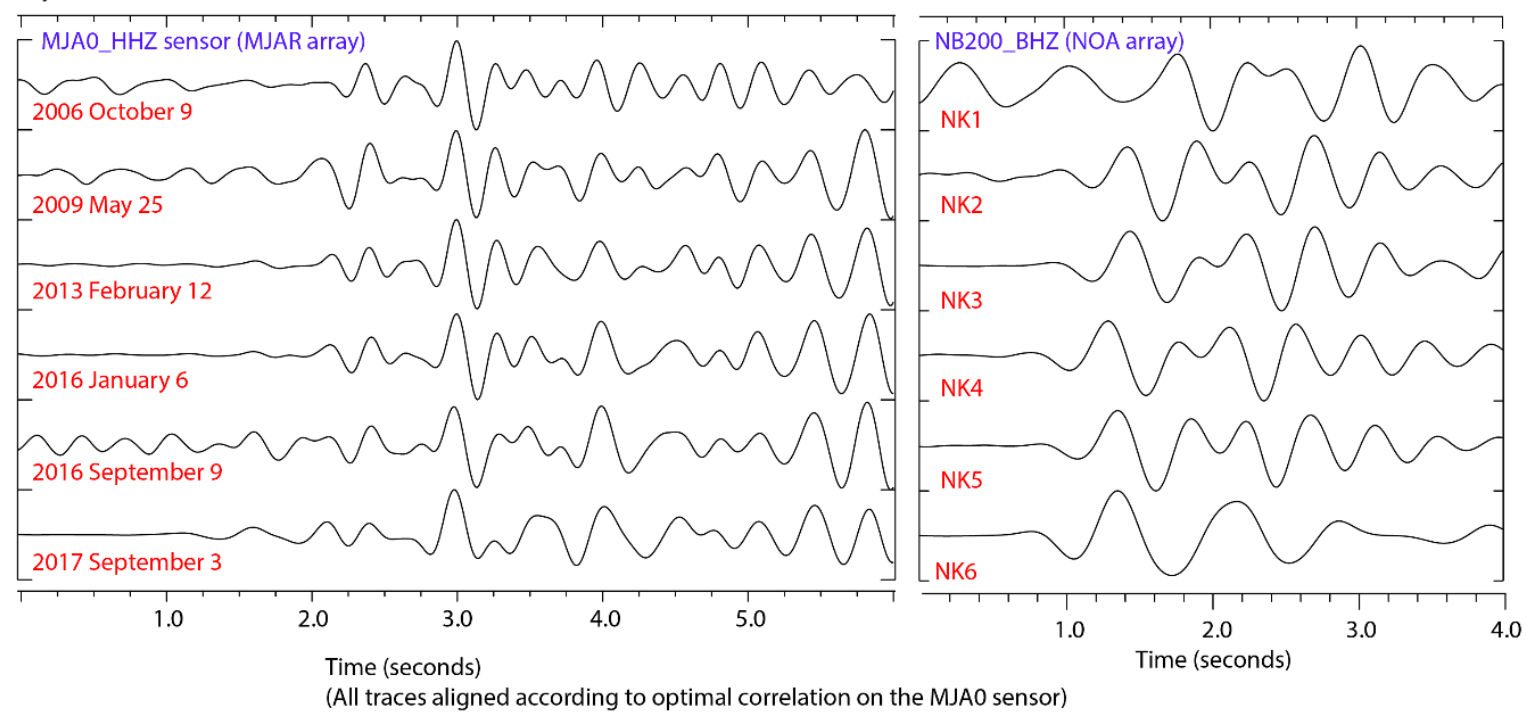

b)

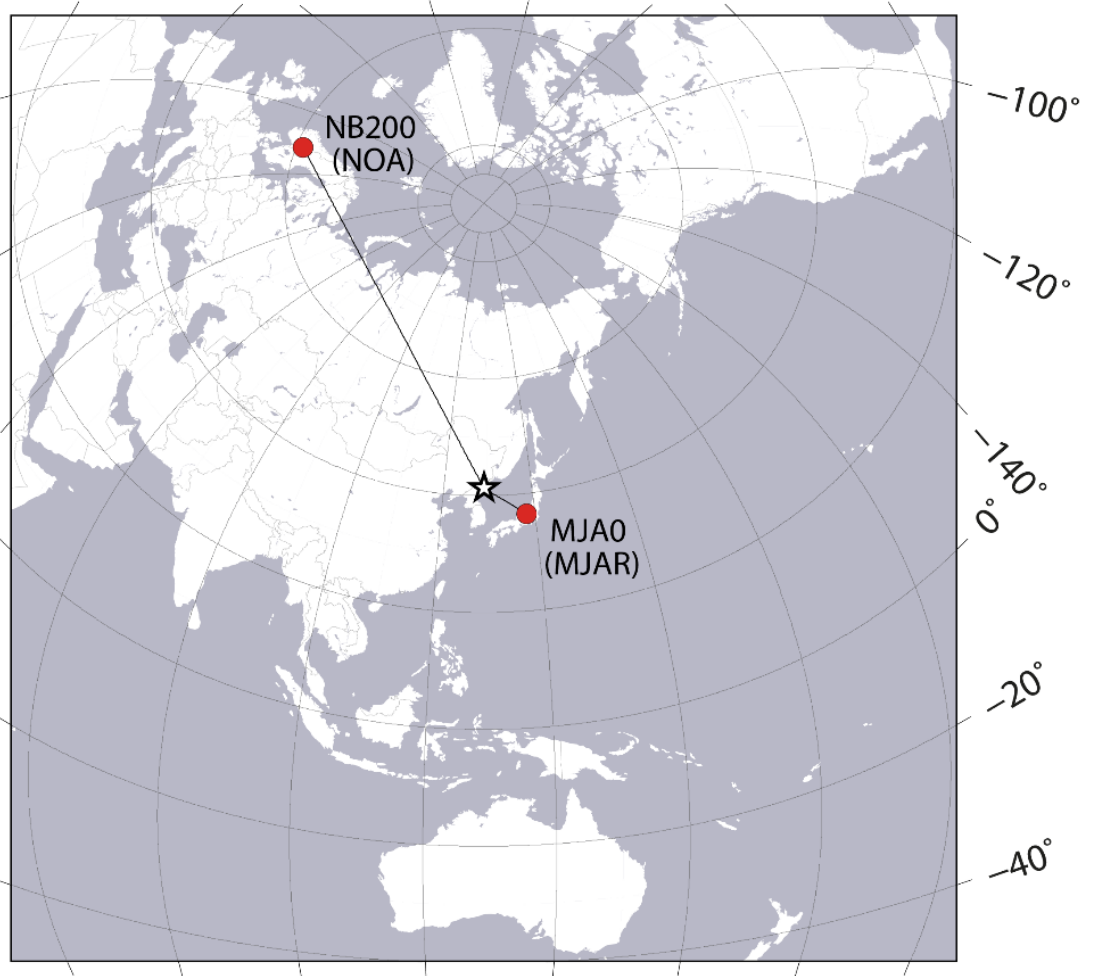

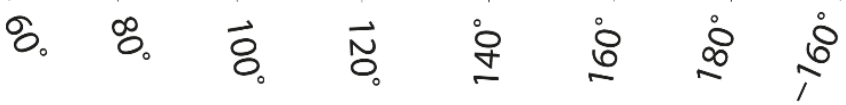

Figure S4. (a) Waveforms for channel MJAO_HHZ of the MJAR array (Japan) and channel NB200_BHZ of the NOA array (Norway). As in Figure S3, the time-shifts applied to the events are identical in left and right panels - fixed to optimize the alignment of the signals in Japan. The frequency band 1.5-3.5 Hz is applied to all waveforms. The traces are scaled individually to have the same maximum amplitude. (b) Map showing locations of the MJA0 and NB200 seismic stations in relation to the DPRK test-site (star symbol). 
Pre-acceptance postprint: final paper published on https://doi.org/10.1785/0220180116 Probing the DPRK Nuclear Test Site down to Low-Seismic Magnitude:

Seismological Research Letters (2018) 89 (6): 2034-2041,

S. J. Gibbons, T. Kværna, S. P. Näsholm, S. Mykkeltveit

As reported on 38 North (https://www.38north.org/2018/05/punggye052518/, last accessed 30 May, 2018), on 24 May, 2018, North Korea carried out a series of explosions in front of representatives from the international press to destroy infrastructure at the Punggye-ri test-site. A map of the tunnel-system with the locations of the explosions was presented at this event (images displayed on the 38north link). It is not clear as to how accurate this map is in providing absolute locations, but the indication is that the 2006 explosion was linked to the East Portal by a straight tunnel ending at the location displayed in Figure S5. The location estimates presented by Gibbons et al. (2017) are shown in Figure S5 with the entire cluster of events translated about 360 meters to the South East in order to make the 2006 and 2009 event locations as consistent as possible with the locations displayed at the press event on 24 May 2018.

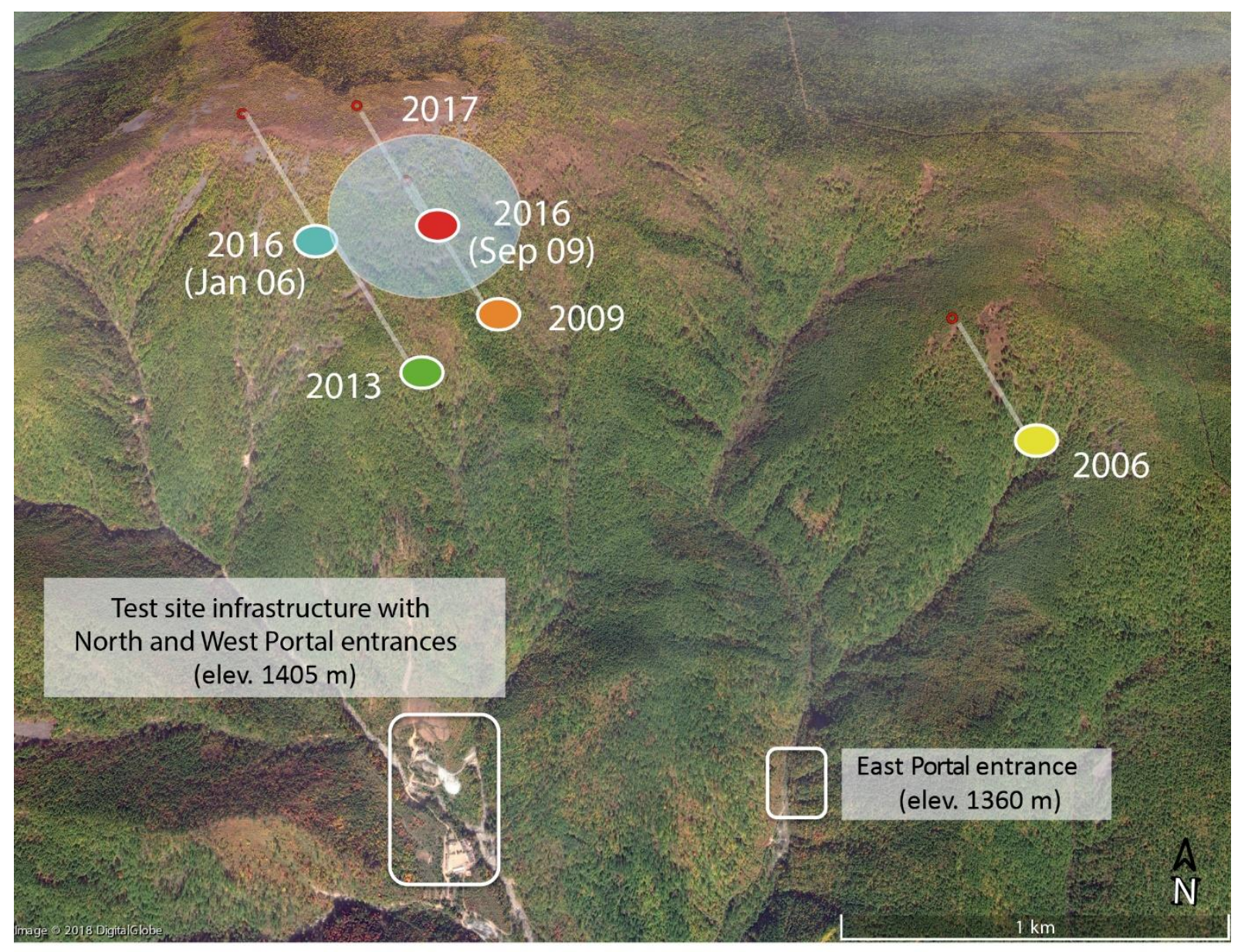

Figure S5. Relative location estimates for the North Korean nuclear tests (Gibbons et al., 2017) shifted to match approximately the locations for the 2006 and 2009 blasts inferred from the tunnel-map presented by the DPRK on 24 May 2018 (https://www.38north.org/2018/05/punggye052518/, last accessed 30 May 2018).

The locations of the 2013, 2016, and 2017 blasts are displayed relative to the 2006 and 2009 explosions as estimated from seismic measurements. The overall picture is consistent with the pattern of published locations although differences between the calculated and published epicenter locations suggest that even more significant departures from the basic seismic wavefield model than assumed may be required in order to reconcile seismic delay time observations with the published locations. 
Pre-acceptance postprint: final paper published on https://doi.org/10.1785/0220180116 Probing the DPRK Nuclear Test Site down to Low-Seismic Magnitude:

Seismological Research Letters (2018) 89 (6): 2034-2041,

\section{S. J. Gibbons, T. Kværna, S. P. Näsholm, S. Mykkeltveit}

The declared DPRK nuclear test of September 9, 2016, (NK5) was followed two days later by a small seismic event (Adushkin et al., 2017). Unlike the collapse event that followed minutes after NK6, this small event of just above magnitude 2 was only detected at the two closest IMS arrays. It is however clear from Figure 56 that, even on the best of the available stations, the signal is weak and the SNR is poor. We see the sharp Pn arrival and the larger amplitude Pg phase in the signal from the September 11 event, together with an apparent Lg signal between 100 and 120 seconds. Despite the low SNR for this signal, the USRK recording is the best available of the stations open to the international community.

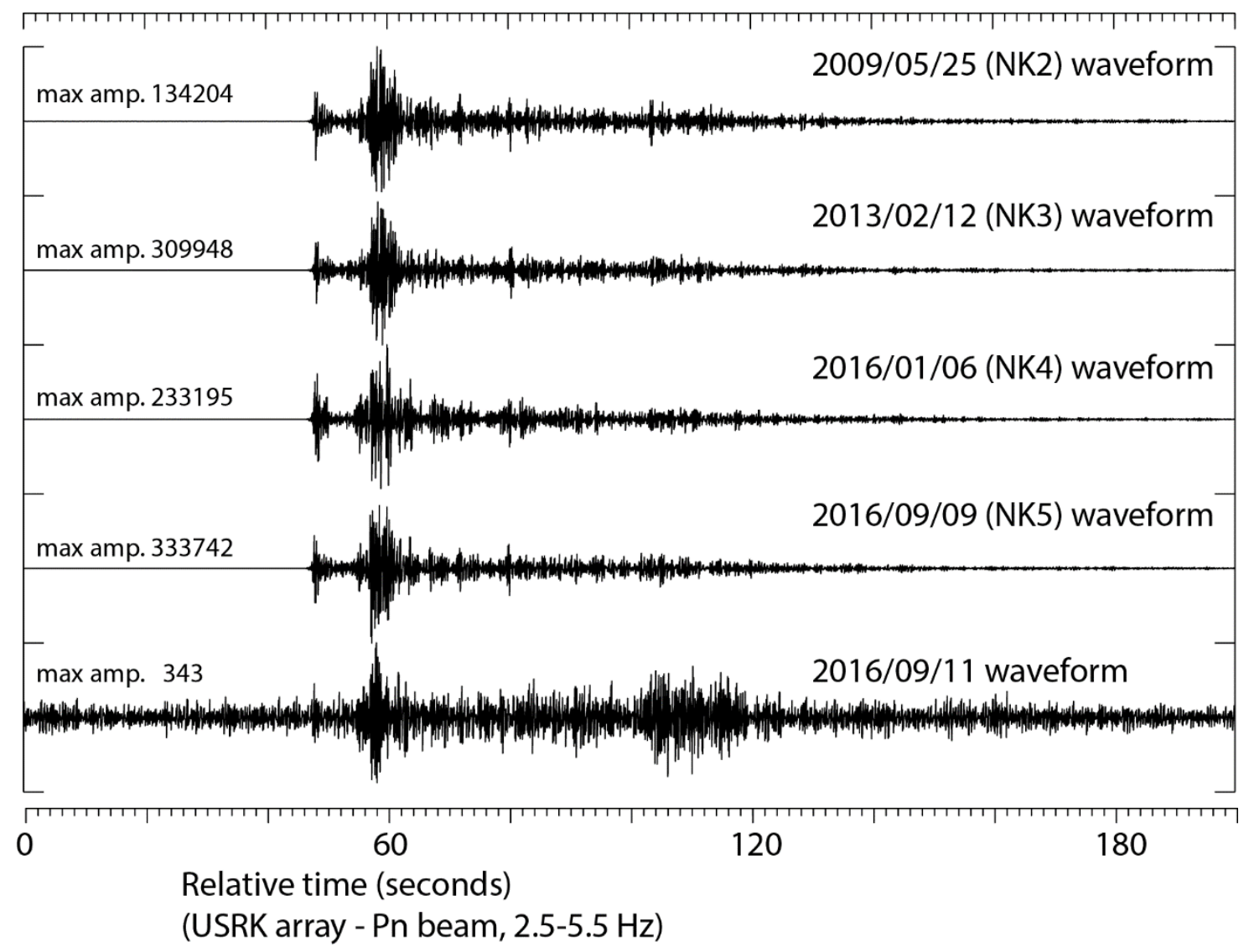

Figure S6 Beams of short-period vertical traces at the USRK array optimized for the Pn arrivals from the DPRK test-site for four declared nuclear tests as indicated and the event on 11 September 2016 (lowermost trace). The high frequency Pn arrival is seen for all events at about 48 seconds with the larger, lower frequency, Pg phase arriving 6 or so seconds later. The smallest event appears to have more energy in the later $\mathrm{Lg}$ phase relative to the Pn and Pg phases than the declared nuclear test signals. All waveforms bandpass filtered 2.2-5.5 Hz and all traces are scaled individually.

The low SNR of the 11 September 2016 signal and poor correlation peaks with waveform templates mean that correlation-based relative time measurements may lack accuracy to the point at which a classical double-difference location estimate is qualitatively incorrect. A systematic comparison of the correlation between the 11 September 2016 signal and each of these template events may provide constraints based upon the waveform similarity alone (e.g. Menke 1999). We deliberately split the full USRK waveforms into separate templates for the $P$ and $S$ parts of the wavetrains. (Since the $S$ part of the signal propagates more slowly than the $P$ part of the signal, a small difference in the epicentral distance may result in degradation of the correlation function simply due to a time-offset between the best-corresponding segments of the wavetrain.) Figure S7 displays the continuous 
Pre-acceptance postprint: final paper published on https://doi.org/10.1785/0220180116 Probing the DPRK Nuclear Test Site down to Low-Seismic Magnitude:

Seismological Research Letters (2018) 89 (6): 2034-2041,

S. J. Gibbons, T. Kværna, S. P. Näsholm, S. Mykkeltveit

cross-correlation traces for both P- and S- templates from 5 different master events in the time window containing the USRK signal for the 11 September 2016 event. (One of the 5 master events is the 11 September event itself.) Here, we also include the autocorrelation - i.e. attempting to detect the signal using its own shape as a waveform template.

The auto-correlation is the lowermost trace in both panels of Figure S7. This function trivially attains a value of unity at the sample where the signal correlates with itself, and is displayed scaled down together with the correlation coefficient traces calculated for the other master events. The autocorrelation functions can provide information about the anticipated symmetry in correlations with other templates and give the impression of how significant a given match may be. (For example, is the effective time-bandwidth product high or low? Is a high value of the correlation coefficient achieved often and trivially, or is it an exceptional occurrence against a low background noise level?) Were there to be genuine waveform similarity between the 11 September 2016 event signal and any of the master events, we would expect a significant maximum for both P- and S-templates at the same times as the peak times in the auto-correlation function. Considering first the correlations with the P-templates from the four UNEs, all master events generate a significant local correlation maximum at the same time as the local maximum for the P-wave auto-correlation. The correlation peaks are significantly larger for the two templates from 2016 (NK4, January 6, and NK5, September 9) than for the February 2013 template (NK3) or the May 2009 template (NK2). The symmetry is greatest, and most similar to the auto-correlation function, for the NK5 template.

For the S-templates, only one of the master events - NK5 on 9 September 2016 - provides a significant local maximum at approximately the same time as the peak in the auto-correlation function. Exactly 45 seconds separates the start of the P-template and the start of the S-template for all the master events. The local maximum in the S-wave template correlation for the NK5 master event occurs 44.985 seconds following the local maximum from the NK5 P-wave template. If we interpret the times of these local correlation maxima as being exact measurements of the delays between the different segments of the wavetrain then this means a 15 millisecond shorter S-P time at USRK for the aftershock than for the explosion, with the consequence that the event was closer to the array than the explosion and hence slightly north of the test-site. We note the significant asymmetry of the S-wave correlation function around this time and note that contributions to the correlation function from parts of the wavetrain with low waveform similarity may introduce bias to this measurement (see Shearer, 1997, for a discussion on the quality of correlation functions for measuring waveform similarity). The correlation local maxima for the S-templates for explosions NK2, NK3, and NK4 are of far poorer quality than for explosion NK5 and there is no justification of choosing an arrival time corresponding to any of these peaks. Is there sufficient evidence in Figure S7 to suggest that the 11 September 2016 event occurred in the immediate vicinity of the preceding explosion, or is it a case of coincidental similarity between unrelated (or low-SNR) parts of the corresponding wavetrains? 
Pre-acceptance postprint: final paper published on https://doi.org/10.1785/0220180116

Probing the DPRK Nuclear Test Site down to Low-Seismic Magnitude:

Seismological Research Letters (2018) 89 (6): 2034-2041,

S. J. Gibbons, T. Kværna, S. P. Näsholm, S. Mykkeltveit

a)

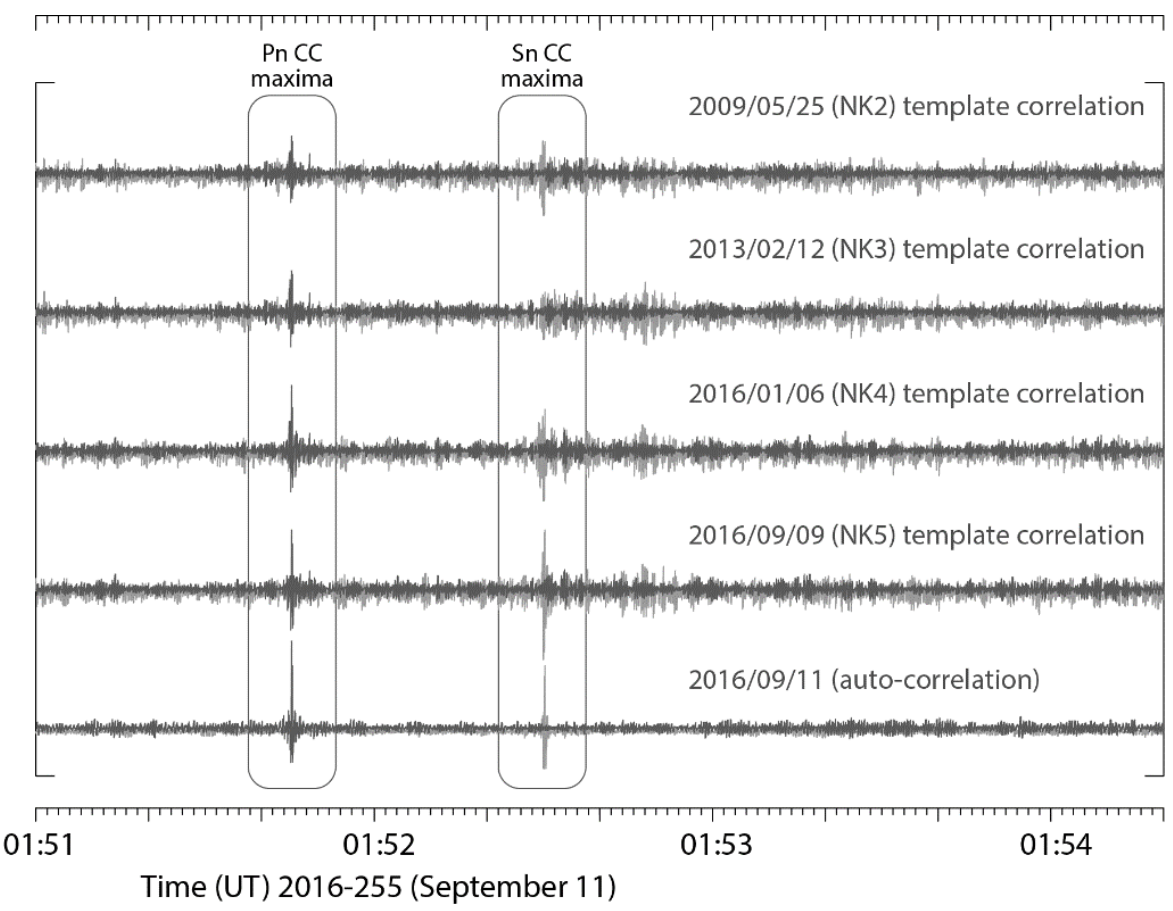

b)

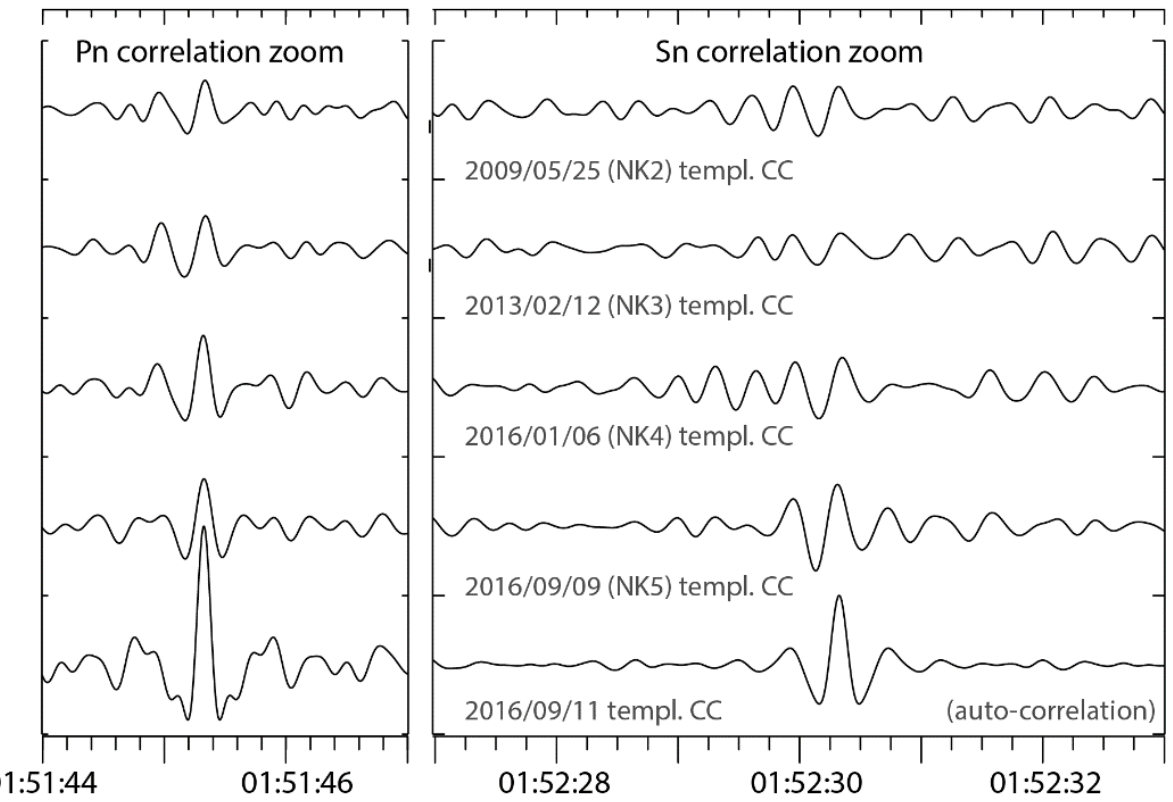

Time (UT) 2016-255 (September 11)

Figure S7 Stacks of correlation coefficient traces calculated using Pn/P-coda and Sn/S-coda templates at the USRK array from the events as indicated over the time-window containing the 11 September 2016 DPRK event. The vertical scaling is identical for each of the traces except for the auto-correlation traces (lowermost line) which have been scaled down to allow a meaningful comparison with the smaller values on the remaining traces. All waveforms have been bandpass filtered 2-6 Hz and the correlation templates for both Pn and $\mathrm{Sn}$ arrivals and coda are $\mathbf{4 0}$ seconds long. 
Table S1 displays a list of correlation detections for events at or close to the DPRK test-site confirmed by both USRK and KSRS arrays with synchronous times. Most of these events occur following NK6 on 3 September 2017, although 5 events were also detected prior to this event: the two events of 25 May 2014, one on 19 July 2013, and two earlier in 2016. A detection was made which points to a small seismic event six hours after NK6 at 09:31:27 UT on 3 September 2017. No signals for this event are visible above the background noise; the only evidence is in the correlation traces. Figure $\mathrm{S} 8$ displays waveforms at both KSRS and USRK for a short time window on Saturday 9 December 2017, together with the corresponding correlation traces for two given waveform templates. In this short time window, three events at or close to the test-site are detected. For one event, there are clear signals visible in the filtered waveforms - this event was detected and classified using conventional seismic processing pipelines. One event, some five minutes earlier, is detected with clear correlation peaks and with the largest amplitude parts of the wavetrain just exceeding the background noise. A third event, about one minute after the first is only just discernable due to two marginal correlation peaks which just happen to occur synchronously between the two arrays. Had such a peak only been detected on a single one of the arrays, it would be difficult not to discard the detection as lacking sufficient evidence. 
Pre-acceptance postprint: final paper published on https://doi.org/10.1785/0220180116

Probing the DPRK Nuclear Test Site down to Low-Seismic Magnitude:

Seismological Research Letters (2018) 89 (6): 2034-2041,

S. J. Gibbons, T. Kværna, S. P. Näsholm, S. Mykkeltveit

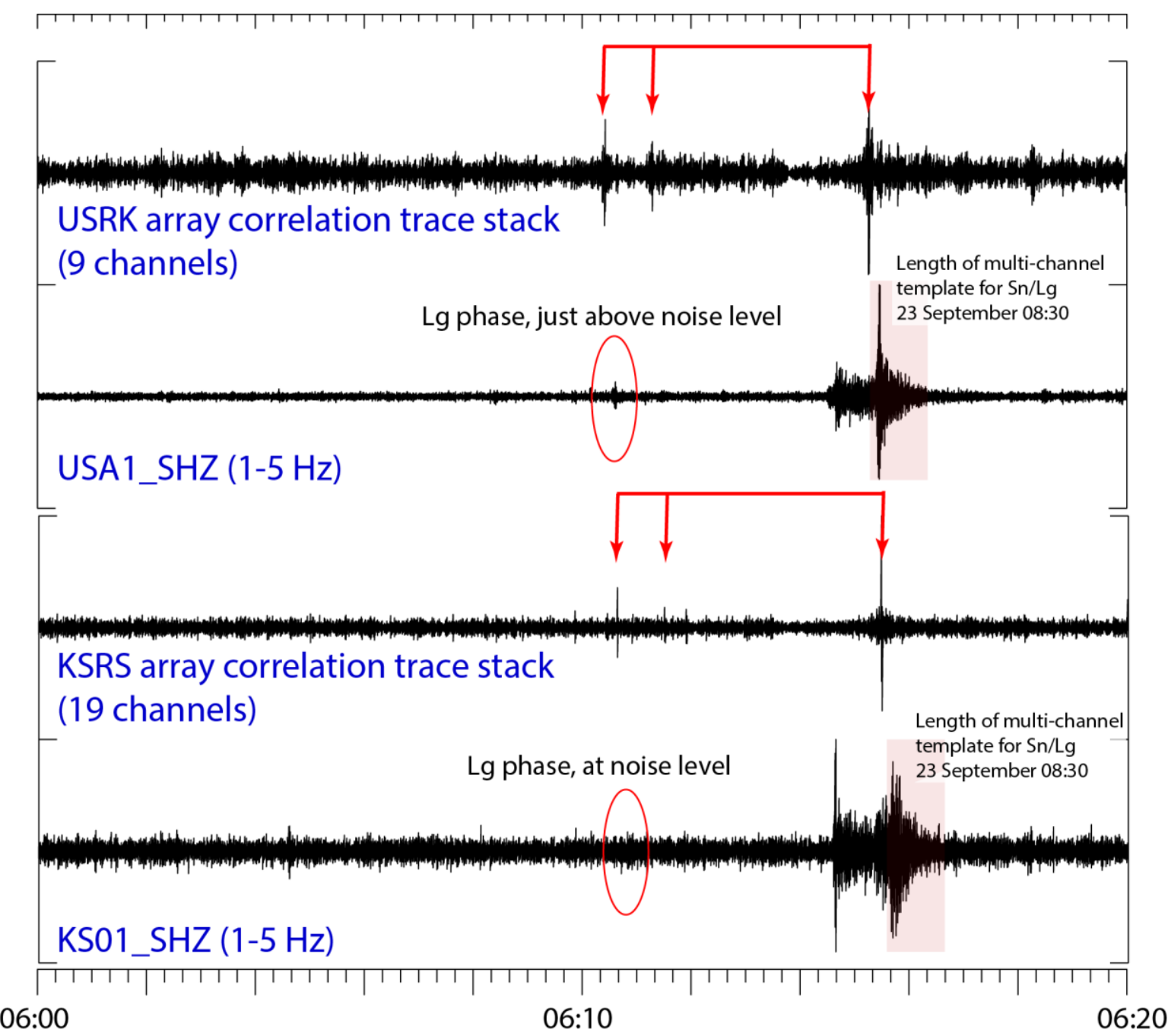

Time (UTC) 2017-343 (December 9, 2017)

Figure S8. Detection of small events at or close to the test-site on 9 December 2017 at the USRK and KSRS arrays using a 60-second-long Sn/Lg template at each array for the 08:30 UT event on 23 September 2017. Only one event has the full wavetrain visible clearly in the waveforms but, in the minutes prior to this event, correlation peaks with identical time-shifts are detected. For the first of these detections, an Lg signal is visible above the background noise level. For the remaining correlation detections, the only evidence we have is the correlation peaks themselves at the different arrays, together with the confirmation of synchronization of the correlation traces at these times (Gibbons and Ringdal, 2006). 
Pre-acceptance postprint: final paper published on https://doi.org/10.1785/0220180116 Probing the DPRK Nuclear Test Site down to Low-Seismic Magnitude:

Seismological Research Letters (2018) 89 (6): 2034-2041,

S. J. Gibbons, T. Kværna, S. P. Näsholm, S. Mykkeltveit

\begin{tabular}{|c|c|c|c|c|c|}
\hline Origin time & Date & $\begin{array}{c}\text { CC_SNR } \\
\text { (KSRS) }\end{array}$ & $\begin{array}{c}\text { CC_SNR } \\
\text { (USRK) }\end{array}$ & magnitude & IDC Late Event Bulletin \\
\hline 2013-200:13.23.50.900 & Fri Jul 19 & 22.0 & 14.1 & & \\
\hline 2014-145:06.01.28.200 & Sun May 25 & 22.1 & 15.1 & & \\
\hline 2014-145:06.43.03.950 & Sun May 25 & 28.2 & 27.5 & & \\
\hline 2016-184:19.52.27.850 & Sat Jul 2 & 144.9 & 12.4 & & \\
\hline 2016-255:01.50.47.300 & Sun Sep 11 & 13.4 & 15.1 & 2.5 & \\
\hline 2017-246:09.31.26.800 & Sun Sep 3 & 17.5 & - & $<2.0$ & - \\
\hline 2017-266:04.42.57.600 & Sat Sep 23 & 288.3 & 401.6 & 2.7 & LEB (mb 2.7) $33 \mathrm{~km}$ from TS \\
\hline 2017-266:08.29.14.400 & Sat Sep 23 & 367.0 & 224.8 & 3.4 & LEB (mb 3.4) $24 \mathrm{~km}$ from TS \\
\hline 2017-285:16.41.06.000 & Thu Oct 12 & 277.1 & 399.9 & 3.2 & LEB (mb 2.7) $29 \mathrm{~km}$ from TS \\
\hline 2017-335:22.45.54.400 & Fri Dec 1 & 113.2 & 150.2 & 2.5 & - \\
\hline 2017-339:14.40.52.050 & Tue Dec 5 & 300.1 & 123.3 & 2.9 & LEB (mb 2.6) $14 \mathrm{~km}$ from TS \\
\hline 2017-339:19.55.52.800 & Tue Dec 5 & 122.6 & 72.8 & 2.2 & - \\
\hline 2017-339:23.30.11.450 & Tue Dec 5 & 36.2 & 69.3 & 2.1 & - \\
\hline 2017-340:16.20.05.800 & Wed Dec 6 & 126.6 & 19.1 & 2.0 & - \\
\hline 2017-343:06.08.41.100 & Sat Dec 9 & 47.2 & 85.9 & 2.2 & - \\
\hline 2017-343:06.09.33.050 & Sat Dec 9 & 20.7 & 20.9 & $<2.0$ & - \\
\hline 2017-343:06.13.32.000 & Sat Dec 9 & 786.5 & 447.0 & 3.3 & LEB (ML 2.9) $8 \mathrm{~km}$ from TS \\
\hline 2017-343:06.40.01.000 & Sat Dec 9 & 561.9 & 295.7 & 2.7 & LEB (ML 2.4) $11 \mathrm{~km}$ from TS \\
\hline 2017-343:07.39.01.400 & Sat Dec 9 & 17.1 & 34.1 & 2.1 & - \\
\hline
\end{tabular}

Table S1: Seismic events at or close to the North Korea nuclear test site between 2008 and 31 December 2017 detected using waveform correlation on both USRK and KSRS seismic arrays. The declared UNEs and the 03:38:30 UT 3 September 2017 collapse event are omitted. 
Pre-acceptance postprint: final paper published on https://doi.org/10.1785/0220180116

Probing the DPRK Nuclear Test Site down to Low-Seismic Magnitude:

Seismological Research Letters (2018) 89 (6): 2034-2041,

S. J. Gibbons, T. Kværna, S. P. Näsholm, S. Mykkeltveit

\section{REFERENCES}

Adushkin, V. V., Bobrov, D. I., Kitov, I. O., Rozhkov, M. V., and Sanina, I. A. (2017), Remote detection of aftershock activity as a new method of seismic monitoring, Doklady Earth Sciences, 473, 303-307, doi:10.1134/s1028334×17030011

Gibbons, S. J. and Ringdal, F. (2006), The detection of low magnitude seismic events using arraybased waveform correlation, Geophysical Journal International, 165, 149-166, doi:10.1111/i.1365-246x.2006.02865.x

Gibbons, S. J., Pabian, F., Näsholm, S. P., Kværna, T., and Mykkeltveit, S. (2017), Accurate relative location estimates for the North Korean nuclear tests using empirical slowness corrections, Geophysical Journal International, 208, pp. 101-117 http://dx.doi.org/10.1093/gii/ggw379

Menke, W. (1999), Using waveform similarity to constrain earthquake locations, Bulletin of the Seismological Society of America, 89, 1143-1146

Shearer, P. M. (1997), Improving local earthquake locations using the L1 norm and waveform cross correlation: Application to the Whittier Narrows, California, aftershock sequence, Journal of Geophysical Research, Solid Earth 102, 8269-8283, doi:10.1029/96jb03228 